\title{
Loan Guarantees for Consumer Credit Markets
}

Kartik B. Athreya, Xuan S. Tam, and Eric R. Young

wo specific subsets of the U.S. population - the young and those with temporarily low income (and wealth) - have long been work has long measured the fraction of constrained households at close to 20 percent of the U.S. population (see Zeldes 1989; Jappelli 1990; and Hubbard, Skinner, and Zeldes 1994). More recent work again places importance on the inability to cheaply access unsecured credit when needed (see, e.g., Gross and Souleles 2002 and Telyukova 2013). While the preceding work takes substantial care to arrive at estimates, even the simplest summary measures in U.S. data suggest a lack of access to consumer credit for the groups mentioned above. For example, among families with heads of household who have income between $\$ 25,000$ to $\$ 50,000,34$ percent have no credit card at all. Moreover, 60 percent roll over debt and pay interest rates of approximately 15 percent per year, a clear indication of their inability to access cheaper alternatives. Among younger families, those with heads of household of age 35-44, similar patterns emerge: 32 percent have no credit card, while 32 percent roll over debt and also pay the same (high) interest rates. Lastly, poorer households fare badly: 55 percent of those with income between $\$ 10,000$ and $\$ 25,000$ have no credit card, while 55 percent of renters

- We thank Larry Ausubel, Dean Corbae, Martin Gervais, Kevin Reffett, and participants in seminars at Arizona State, Georgia, Iowa, and the Consumer Credit and Bankruptcy Conference at the University of Cambridge for helpful comments and discussions. We also thank Brian Gaines for his editorial assistance. We especially thank Borys Grochulski, Robert Hetzel, and Miki Doan for detailed comments, and Edward Prescott for his guidance as editor. The opinions expressed here are not necessarily those of the Federal Reserve Bank of Richmond or the Federal Reserve System. E-mail: kartik.athreya@rich.frb.org. 
don't have a credit card. ${ }^{1}$ The lack of wealth among both young and low-income households also precludes the use of far less expensive secured credit, such as home equity loans or lines of credit. Thus, despite the apparent ubiquity of consumer credit, the young and the poor both appear to face tight restrictions on access to the principal source of credit available to them.

The populations most routinely identified as credit constrained are also precisely those groups who are generally most lacking in wealth that could be pledged as collateral. For example, the young and poor do not possess sufficient collateral. In the student loan market, the private sector's inability to attach human capital in the event of default has been viewed as a basis for credit policy since at least Becker (1967). More recently, and very specifically to our inquiry, quantitative work suggests that the market for unsecured consumer credit is significantly hindered by the availability of low-cost personal bankruptcy (see, e.g., Chatterjee et al. 2007; Livshits, MacGee, and Tertilt 2007; or Athreya 2008) and by the presence of private information about borrower default risk (e.g., Sánchez 2009; Athreya, Tam, and Young 2012b). The absence of collateral is important: Full collateralization will, by definition, make both limited-commitment and private-information frictions irrelevant to lending decisions. In other words, it is the unsecured credit market whose functioning is likely to be most important for the populations identified above.

Given that the unsecured credit market is the one most central to the consumption-smoothing objectives of a significant share of U.S. households, the question is then: What, if anything, can be done in this market to improve outcomes? A first answer might be to make bankruptcy law tougher: If limited commitment is the problem, why not directly address the issue by making debt harder to repudiate? The problem is that while formal bankruptcy is a currently important source of credit losses, informal default remains, in practice, a clear option. Recent work of Athreya, Tam, and Young (2012b) suggests that this option seriously limits the power of bankruptcy policy to diminish incentives for debt repudiation, and, hence, to mitigate limited commitment as an impediment to unsecured consumer lending. That is, once calibrated to match the salient facts on consumption and borrowing, informal default remains a viable option that borrowers choose in the face of even modest increases in the cost of formal bankruptcy. This is seen in the data in terms of the high rate of bankruptcy and

\footnotetext{
${ }^{1}$ Source: www.census.gov/compendia/statab/2012/tables/12s1189.pdf. The unit is the family in the 2007 Survey of Consumer Finances, and the sample is before either the deleveraging or Great Recession. All dollars are 2007.
} 
delinquency in unsecured credit in U.S. data. However, even if incentives to default are difficult to alter, an alternative already employed in a wide array of settings - but not yet for unsecured consumer creditseems promising: public loan guarantees.

Such guarantees work by using public funds to defray private losses from default. In the United States, the most obvious loan guarantee programs for households are those that accompany home loans. For example, the Federal Housing Administration (FHA) and the Veterans Administration both offer loan guarantees to private lenders, and, in both 2009 and 2010, the FHA alone issued roughly two million guarantees and, as of 2010, insured nearly one-tenth of the stock of outstanding U.S. mortgage debt. Similarly, the U.S. Student Loan Administration (Sallie Mae) is active in arranging guaranteed loans, with recent flows on the order of $\$ 100$ billion annually and a stock of approximately $\$ 500$ billion. Loan guarantees also play a sizeable role in credit to households attempting self-employment, with the U.S. Small Business Administration's (SBA) 7a loan program guaranteeing roughly $\$ 100$ billion in credit per decade since $1990 .^{2}$ However, despite their similarity to the programs we study in this article, the closest analogy might be instead to flood insurance. The reason for this will be made explicit below but stems from the fact that in our model, loan guarantees act in a manner that lowers the cost of moving consumption across both time and states-of-nature, in much the same manner as a subsidized form of insurance might.

The goal of this article is not to analyze a specific extant policy but rather to take a first step, within a specific model class, toward understanding the potential gains from extending loan guarantees to unsecured consumer credit markets. As such, and especially because they are currently not in use, some motivation for why one might study loan guarantees, as opposed to any number of other interventions in consumer credit markets, deserves discussion.

\footnotetext{
${ }^{2}$ In addition to these officially guaranteed loan programs, there is one that dwarfs them all, and this is the one operated by the two main government-sponsored enterprises, Fannie Mae and Freddie Mac. These entities issue securities to investors that come with a guarantee against default risk. The ultimate originators of mortgage credit taken by homebuyers thereby receive, in essence, a loan guarantee. While such guarantees have historically not been backed by the Treasury, they now clearly are: mortgagebacked securities investors receive Fannie and Freddie guarantees on loans with a face value of approximately $\$ 5$ trillion, nearly half of the value of all household mortgage debt. See Li, (2002), Walter and Weinberg (2002), and Malysheva and Walter (2013) for more details. These articles show that the overall contingent-liabilities of the U.S. government have grown substantially over time. Lastly, beyond their sheer size, the scope of activities receiving guarantees is noteworthy. Endeavors ranging from nuclear power plant construction, trade credit, microenterprises, and support for female entrepreneurs all currently receive loan guarantees.
} 
One important reason to view loan guarantees as potentially valuable in improving credit access is that under competitive conditions, loan guarantees decouple loan pricing from credit risk. This is relevant for two reasons. First, a growing body of work shows that in the absence of complete insurance markets, risk-averse households can benefit from the state contingency introduced by the option to default in bad states of the world (see, e.g., Zame 1993; Dubey, Geanakoplos, and Shubik 2005; Chatterjee et al. 2007; and Livshits, MacGee, and Tertilt 2007). What this means, intuitively, is that while nondefaultable debt requires the borrowers to always repay debt as promised, once default is allowed, matters are not so stark. Why? Because a borrower in dire straits can now invoke the option to not repay debt if doing so in the current period would expose them to severe hardship. This is what is meant by "state contingency." In a world where such an option is present, given the absence of other more explicit forms of financial contracts to help deal with risk, most notably insurance contracts against income loss, defaultable debt can be beneficial to borrowers.

Moreover, in existing work, consumers have been shown to benefit despite the presence of loan pricing that moves "against" the riskiest borrowers. However, these gains are not necessarily accessible in all $a$ priori plausible environments. In recent quantitative work on the value of defaultable consumer debt, a variety of authors (such as Athreya, Tam, and Young 2009) have found that in many cases the ability of lenders to reprice loans at the same frequency as the arrival of new information on income risk undoes insurance benefits altogether. In other words, every time a consumer is hit by a persistent (but not permanent) bad shock, she will find her ability to commit to loan repayment eroded, and any borrowing she might attempt will become expensive. From the perspective of borrowers, if competitive lenders are made partially whole, they cannot "risk adjust" interest rates as much and so such loans will better assist households in consumption smoothing. Indeed, in the context of boosting aggregate consumption, researchers have recently started considering ways to direct unsecured credit to households at "favorable interest rates," with the public sector bearing default risk, exactly as would occur under the loan guarantees to consumers we study. ${ }^{3}$

Second, if information on borrowers has improved secularly over time, as has been suggested by many as having occurred in recent decades in U.S. consumer credit markets (see, e.g., Sánchez 2009; Athreya, Tam, and Young 2012b; and Narajabad 2012), then loans

\footnotetext{
${ }^{3}$ They are referred to as federal lines of credit. Details are here: wwwpersonal.umich.edu/ mkimball/fiscal-bang-for-buck-29may12.pdf.
} 
are now priced more accurately. This is likely to make relatively risky borrowers' access either worse or improve it by less than that of safer borrowers. Indeed, Sánchez (2009) suggests that this will be the case. Moreover, improvements in information will certainly bring the risk sensitivity of loan pricing closer to what we study below in the "full information" (FI) case. In these cases, as noted above, standard models suggest that unsecured credit will not work well as a smoothing device. Thus, policies that allow for default but break the link between credit risk and credit pricing are promising candidates to improve allocations - at least to borrowers. ${ }^{4,5}$

Despite their likely benefits, loan guarantees will create costs, particularly in two places. First, default rates are likely to rise, generating more deadweight loss (whether pecuniary or nonpecuniary in nature). The rise in default rates occurs for the very reason that loan guarantees "work": They lead to the systematic underpricing of loans by lenders, given their risk. Relatively larger loans will now attract relatively high-risk borrowers. As a result, the more effective any loan guarantee scheme is in spurring borrowing and consumption, the more prevalent that default and deadweight losses will be on the equilibrium path. In the context of loan guarantees for entrepreneurial ventures, the work of Lelarge, Sraer, and Thesmar (2010) documents precisely this type of response in a near-natural French experiment. As they note, "it [loan guarantee] significantly increases their probability of default, suggesting that risk-shifting may be a serious drawback for such loan guarantee programs." This inevitable tradeoff means that the real questions are: "By how much?" and "does risk-shifting happen, and if so, is it welfare-enhancing?" 6

\footnotetext{
${ }^{4}$ In addition to decoupling risk and pricing, loan guarantees will also reduce average interest rates, all else equal. This is relevant for two reasons. First, concern with the consequences of frequent repricing of consumer debt has already led to policy changes. Most noticeably, the CARD Act of 2009 has responded by essentially requiring longerterm commitments from lenders in an attempt to deter frequent repricing. However, as studied by Tam (2009), such policies may carry serious side effects. In particular, average interest rates are predicted to rise substantially to offset the ability of a borrower to "dilute" his debt (much as in the sovereign debt literature). Second, average borrowing rates are likely important for welfare: Calem, Gordy, and Mester (2006) show that many U.S. households appear to use credit cards for relatively long-term financing, making the roughly 10-percentage-point cost differential between secured and unsecured interest rates quantitatively important.

${ }^{5}$ Andolfatto (2002) develops a simple model to illustrate how government policies (e.g., interest rate ceilings) may induce unintended outcomes (e.g., credit constraints) that generate calls for further policies to deal with these side effects (e.g., loan guarantees). A related point is that to the extent that public insurance simply crowds out familial or other forms of private insurance, the effects will be overstated. This possibility is not addressed in our article, and so should be kept in mind.

${ }^{6}$ With respect to the federal lines of credit noted earlier, and the subsidy that will allow the scheme to affect allocations (unlike the actuarially fair arrangement that
} 
Additionally, tax revenue must be raised to finance transfers to lenders ex post. Under incomplete markets, the taxes used to finance these transfers have two opposing effects on welfare. First, if, as was the case in the in study of Lelarge, Sraer, and Thesmar (2010), a relatively large fraction of households faces a tax that a relatively small proportion benefit most significantly from, the introduction of a publicly funded loan guarantee program will reduce the mean level of income for many households. In particular, if it is a relatively small measure of households who run up substantial debts that, absent the guarantee, would demand high interest rates, they then receive a transfer from all other households. Second, nonregressive taxes reduce the variance of after-tax income, especially when one's expected lifetime income (as captured by ex ante uncertainty over one's eventual educational attainment) is uncertain.

While ours is not a policy evaluation article, the model class we study contains features that we believe will be essential to include in any empirically relevant policy related to consumer credit access. Specifically, our model contains a well-defined life cycle for household income that motivates credit use for intertemporal smoothing and uninsurable risk that motivates the use of credit to smooth across states. Importantly, our model features credit constraints that are endogenously derived in response to a limited commitment friction and, in other cases, to asymmetric information as well. Before proceeding, we also note that there is a distinction between what we study here and a more complicated alternative that in some ways may be more natural: We are interested in the implications of the replacement of the current nonguaranteed system with one in which guarantees necessarily apply to loans below a certain size threshold. Future work will, ideally, allow for the addition of guaranteed consumer lending as an option, with households self-selecting into programs with and without loan guarantees.

Our results can be summarized as follows. First, we find in our model that loan guarantees are powerful in influencing allocations: Even modest limits on qualifying loan size invite very large borrowingas perhaps intended by proponents. However, these same limits also bring very large increases in default rates relative to a world without guarantees and, as a result, transfer resources in significant amounts from the ex post lucky to the ex post unlucky, in addition to transferring

we show is irrelevant), the idea's originator, professor Miles Kimball of the University of Michigan, argues as follows: "I am assuming the government will lose money doing this - just not as much as if they handed the money away as a tax rebate with no obligation of repayment. The losing money part would stop private lenders cold [emphasis ours]." 
wealth across education types. Indeed, this is the key tradeoff that differentiates our work from existing research on unsecured credit, such as Chatterjee et al. (2007) or Livshits, MacGee, and Tertilt (2007). These articles find some gains from lax bankruptcy despite the fact that such rules make borrowing more expensive and, hence, tighten credit constraints, as such rules provide valuable insurance. By contrast, our article shows that loan guarantees can improve welfare despite greater ex-post deadweight loss due to bankruptcies, as they make borrowing cheaper and, hence, provide insurance as they relax borrowing constraints.

Second, we find that loan guarantees yield significant benefits as long as they are not too generous (whereby only small loans qualify). At low levels of the guarantee, this welfare gain is disproportionately experienced by low-skilled households who face flat paths for their average income over the life cycle and the risk of relatively large shocks. As loan guarantees are made more generous, however, higher-skilled types rapidly begin to experience welfare losses. This occurs because loan guarantees induce a transfer from skilled to unskilled households, which can be substantial, while the gains to skilled households from improved loan pricing as a result of guarantees are relatively small.

Third, we show that restricted guarantees clearly dominate unrestricted programs in terms of welfare. As noted, households in our model face risk, including that of large negative income shocks. It is plausible, therefore, that a more conditional loan guarantee program, available only to households hit by such shocks, might allow policymakers to provide the benefits from guarantees while limiting their cost. The model thus suggests that this intuition is likely to be valid.

In the case of asymmetric information, the size of this friction will be endogenous as well and will depend on how heterogeneous borrowers are, not only in terms of both exogenous shocks, but also in terms of endogenously determined and unobservable net asset positions. One of the earliest studies of loan guarantees is that of Smith and Stutzer (1989). These authors show in a stylized model with two types of borrowers (high risk and low risk) that the reduction in the sensitivity of loan interest rates to default that accompanies loan guarantees also reduces the high-risk types' incentives to reduce their borrowing inefficiently simply by mimicking the low-risk types. This incentive effect contributes positively to the welfare impact of loan guarantees. And while private information may not currently be a crucial problem in U.S. consumer credit markets, given extensive recordkeeping and information sharing via credit bureaus, it was likely present both in the United States in earlier periods (see Sánchez 2009 and Athreya, Tam, and Young 2012b), and plausibly remains an impediment in 
developing countries currently. A goal of this article is to measure the effects of loan guarantees under these more difficult circumstances. We find that under private information, the gains from guarantees are meaningfully larger than in the absence of private information, quantitatively consistent with the prediction of Smith and Stutzer (1989).

It is important to recognize that loan guarantees can only matter for allocations and welfare when debt is imperfectly collateralized. Even when a loan guarantee program is nominally targeted at a secured form of lending, such as mortgage loan guarantees, they can only alter allocations because there is a positive probability of the loan becoming at least partially unsecured ex post. This leads us to focus on the effects of introducing guarantees for uncollateralized consumer lending, which is the most prominent form of unsecured credit. ${ }^{7}$ Nonetheless, our setting will clearly be informative for the effects of loan guarantees in any market in which there exists states of nature where repayment is less attractive than paying the costs of default. ${ }^{8}$

Our article is linked to three strands of research in public interventions in credit markets. First, our focus on consumer credit with default risk connects this article closely to recent work of Chatterjee et al. (2007); Livshits, MacGee, and Tertilt (2007); Athreya, Tam, and Young (2012b); and Narajabad (2012). In this line of work, however, guarantees are not studied, but both voluntary default and asymmetric information have been shown to matter for the allocation of consumer credit in the absence of guarantees (see, e.g., Sánchez 2009 and Athreya, Tam, and Young 2012b). As noted earlier, our research is novel in studying a distinct mechanism from this strand of work, whereby welfare can be improved by relaxing constraints, rather than tightening them through the promotion of debt forgiveness.

Second, our work is clearly connected to more recent research on quantitative analysis of the allocational consequences of loan guarantees. This work began, to our knowledge, with Gale (1990) and was followed by the rich, fully dynamic, and relatively tractable incompletemarket models developed in Li (1998) and Jeske, Krueger, and Mitman (2010). The last article is the first to focus centrally on credit markets in a consumption smoothing context. However, with respect to

\footnotetext{
${ }^{7}$ See, e.g., Federal Reserve Release G.19: www.federalreserve.gov/releases/g19/ Current/g19.pdf.

${ }^{8}$ Sometimes, these costs are primarily those arising from the surrender of tangible collateral that, ex post, becomes less valuable than reneging on the repayment obligation, e.g., as recent house price declines have done (Ghent and Kudlyak 2011). In other cases, default implies the destruction of intangible collateral, as described above. But in all cases, loan guarantees fundamentally concern unsecured lending.
} 
modeling default, in all the preceding work, default is involuntary. ${ }^{9}$ Our article is also related to recent work of Jia (2013), who in turn builds on Li (1998) to study loan guarantees for firms in a setting where the government's relative (and absolute) financing advantage in recessions can be put to use by providing loan guarantees for small businesses. Our focus, by contrast, is on households, and a main goal is to provide a quantitative analysis that is rich and aims to evaluate consumption smoothing, not investment in small business as these other articles do.

Third, our work relates to an earlier, relatively stylized class of articles that focus on the role of interventions, including loan guarantees, on outcomes for a general problem of risky-investment in static or near-static settings under asymmetric information. Key landmarks in this category are Chaney and Thakor (1985), Smith and Stutzer (1989), Gale (1990), Innes (1990), and Williamson (1994). ${ }^{10}$ Most of this work abstracts from the financing of guarantee programs as well. By contrast, these costs will feature prominently in our analysis. ${ }^{11}$

\section{ILLUSTRATIVE MODEL}

The friction faced by households stems, ultimately, from their inability to explicitly insure income shocks and their inability to credibly promise

\footnotetext{
${ }^{9}$ In future work, we aim to analyze the role of guarantees for mortgage lending. However, the central role of aggregate risk in driving home-loan default makes a full quantitative analysis that satisfactorily incorporates the forces we do allow for herepartially endogenously asymmetric information and limited commitment - currently infeasible. But that model would have the same fundamental structure as the one developed here.

${ }^{10}$ In related work, Lacker (1994) investigates whether adverse selection problems necessarily justify government intervention in credit markets. When cross-subsidization between private contracts is not feasible, intervention is generally welfare-improving.

${ }^{11}$ While substantially different than our model, it is important to note the early work of Smith and Stutzer (1989), who provide a simple argument for the use of loan guarantees in unsecured commercial credit markets - compared to direct government loans or equity purchases, loan guarantees are the only option that does not worsen the private information problem. The interest rate reductions apply to all risk types, so high-risk types do not find any particular advantage, beyond what they already have, for pretending to be low risk. Other programs, such as direct loans to those unable to obtain credit (who are low risk in their model), will lead to additional incentives by high-risk borrowers to claim the contracts intended for low-risk ones, a situation that is harmful to efficiency. Two important distinctions between our work and theirs are worth keeping in mind-the nature of the commitment problem and the issue of government revenue balance. In Smith and Stutzer (1989), limited commitment is a trivial consideration: Default occurs when the borrower receives zero income and is costless (in terms of direct costs). In contrast, U.S. bankruptcy procedures are voluntary and clearly not costless: There is a filing fee in addition to substantial time costs and some form of stigma/nonpecuniary costs appear relevant as well (see Fay, Hurst, and White [1998] or Gross and Souleles [2002]). Smith and Stutzer (1989) do not consider the financing of such payments; any welfare gains from the guarantee could easily be wiped out by the cost of taxation. In contrast, a central aspect of our analysis is the requirement that transfers required to implement loan guarantees be paid for via taxes.
} 
to always repay loans. Given default risk, competitive lenders will be forced to price loans in a way that allows them to break even. As a result, in general, households with differing levels of default risk will face different prices for credit. However, the fact that loans in our model will be priced to reflect default risk also means that some borrowers will find themselves facing expensive credit terms precisely when they most need to borrow. It is these groups who will find guarantees most helpful.

Before turning to the quantitative setting in the next section, it is useful to describe a simple two-period variant of our model to more clearly identify the types of individuals who are affected by risk-based pricing that, by definition, makes borrowing expensive when future income levels might remain low, and who may therefore gain from loan guarantees. Let $c_{i}$ denote consumption in period $i=1,2, e_{i}$ denote the endowment of the consumption good received by the agent in period $i=$ 1,2 , and $d_{2} \in\{0,1\}$ denote the default decision in period 2. Defaulting implies that the consumer incurs a nonpecuniary cost $1 / \lambda$. To remain consistent with the quantitative model on which the final results are based, and for mnemonic ease, a high value of $\lambda$ implies a high risk of default, all else equal, because it implies a low value for the term $1 / \lambda$, which is what gets subtracted from utility in the second period in the event of default. This cost is a stand-in for the variety (and entirety) of costs associated with defaulting and is meant to tractably encompass not only the explicit costs (e.g., bankruptcy filing costs, legal costs, etc.) but also the nonpecuniary costs (e.g., difficulty renting durable goods, obtaining employment, emotional distress, etc.). The dependence of default risk on loan size leads loan prices to depend on loan size.

Households are modeled as borrowing through the issuance of debt with a face value $b<0$. "Face value" refers to the amount that the household is obligated to repay and is the value that it would deliver if it did not default. However, the household may, in period 2, elect to exercise its default option. As a result, the face value of debt, by virtue of being risky, will be discounted by lenders. The term $q(b) \in[0,1]$ is the discount factor applied to a debt issuance of face value $b$ and is determined by competitive markets. To see how this discount is determined, consider a lender wishing to price a loan with face value $b$. Let the default probability for this loan be given by $\pi(b)$. Thus, the expected value of the loan is $(1-\pi(b)) b$. In facing this, the lender must decide what discount $q(b)$ to apply. Competition among lenders implies that the discount allow the bank to, at best, break even on average. This implies that $q(b) b$, the real expected value of resources transferred to the borrower, must have the same cost for the lender to obtain as the expected value of the loan. Let the cost of funds for the lender be 
given by $(1+r)$. Thus, the cost of making a loan with face value $b$ with discount $q(b)$ is $(1+r) q(b) b$. Equating this with the expected value of the loan, $(1-\pi(b)) b$, and simplifying gives

$$
q(b)=\frac{1-\pi(b)}{1+r} .
$$

This is intuitive. As $\pi(b)$ rises, $q(b)$ falls and hits zero when $\pi(b)$ reaches unity (certain default). For loans where $\pi(b)=0$, the discount is simply $\frac{1}{1+r}$, the competitive price of a risk-free loan.

Given this credit market and endowment structure, households choose consumption, borrowing, and saving to maximize standard expected utility preferences:

$$
\max _{c_{1},\left\{c_{2}\left(e_{2}\right), d_{2}\left(e_{2}\right)\right\}}\left\{u\left(c_{1}\right)+\beta E_{e_{2}}\left[u\left(c_{2}\left(e_{2}\right)\right)-d_{2}\left(e_{2}\right) / \lambda\right]\right\} .
$$

Default risk arises in the model from the fact that endowments are probabilistic and structured as follows: All households receive $e_{1}$ in the first period and this value is a known constant. Households face uncertainty with respect to income only in the second period- $e_{2}$ is drawn from a two-point distribution: $e_{2} \in\left\{e_{L}, e_{H}\right\}$ with probabilities $p_{L}$ and $1-p_{L}$.

Households may save or borrow in the first period, denoted $b$, with $b_{1}>0$ corresponding to saving and $b_{1}<0$ being borrowing. In period 2 , they first draw income $e_{2}$, and then elect to default $\left(d_{2}\left(e_{2}\right)=1\right)$ or not $\left(d_{2}\left(e_{2}\right)=0\right)$. Note clearly that if they default, they repay nothing (default is total). This is a useful simplification, but can be relaxed to allow partial default. If they do not default, households must repay the face value they issued in the first period, $b$. As a result, the households' choices are restricted by the following pair of budget constraints. In period 1 ,

$$
c_{1}+q(b) b \leq e_{1}
$$

In period 2, they face

$$
c_{2}\left(e_{2}\right) \leq b\left(1-d_{2}\left(e_{2}\right)\right)+e_{2} .
$$

Consider a case with two types of households. Let one type be those whose second-period endowments $e_{2}$ have a high mean relative to their period 1 value and (relatively) small variance. In other words, income in the future is expected to be higher than today and relatively safe as well; this group roughly corresponds in the data to relatively highly educated borrowers. This group values access to credit because it helps them bring their high, safe, future income into the present. Thus, loan prices for such households will be at the risk-free rate for a relatively wide range of borrowing levels, as the household will elect 
Figure 1 Equilibrium in Two-Period Model

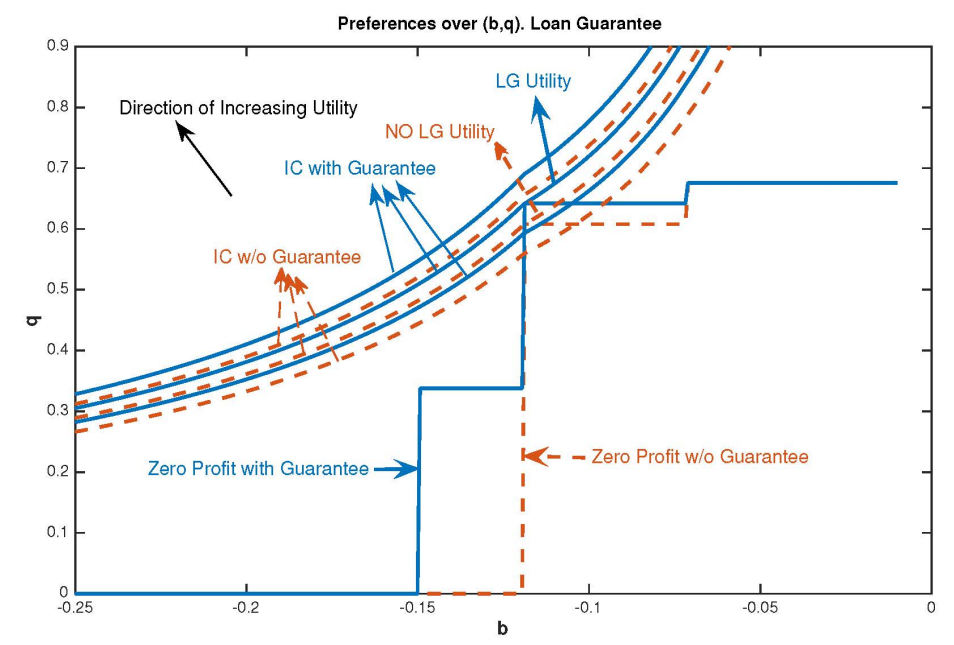

to repay irrespective of the realization of $e_{2}$, and then fall abruptly when the loan size reaches a threshold where households would first begin to consider default. For households facing only small uncertainty about $e_{2}$, this means that once default in one state becomes attractive, it generally becomes attractive in the other state (since they are, by construction, similar). This is easiest to see in the limit where $e_{2}$ is known in period 1 with certainty: For a given loan size $b$, default in period 2 either occurs none of the time or all of the time.

The second type of household we are interested in has small mean and large variance of $e_{2}$; one can think roughly of this group as being relatively less educated and facing greater risk of unemployment in period 2. For these households, borrowing is not particularly useful, but if undertaken, can yield more variation in terms because the default decisions will differ more substantially across realizations of second period income $e_{2}$.

Figure 1 shows a typical situation faced by either type of household. ${ }^{12}$ The indifference curves are monotone (over the range of interest

\footnotetext{
12 The figures represent outcomes under the following parameterization for the endowments of each group. For the first group of agents, three conditions hold: (i) the amount that can be feasibly repaid in the bad state is large (that is, $e_{L}$ is relatively big); (ii) the household will default in both states under risk-free pricing (in the case where $\lambda$ is small relative to $e_{L}$ and $e_{H}$, and the latter are close together); and (iii) the
} 
at least), and reflect the fact that a household can, in principle, receive additional consumption today in two ways: hold $b$ fixed, as long as it faces a higher $q$, or increase borrowing $b$, but accept that the discount $q$ will fall as default risk rises (though not so rapidly that $q(b) b$, which is what the household receives, falls). ${ }^{13}$ At the optimum the household is constrained, in the sense that additional borrowing is desired but not feasible due to the increase in the probability of default; this situation will be typical in the quantitative model as well. Thus, local to that optimal $b$ there are welfare improvements available to households if $q$ can be held fixed while $b$ is increased. This is an obvious point, perhaps, but it is useful to keep in mind as it is the source of the ability of loan guarantees to assist households in smoothing consumption.

\section{Loan Guarantees}

We now introduce a publicly funded (via taxes that, in this section, will remain unmodeled) loan guarantee into this model economy. Loan guarantees will be defined by two parameters: (i) a "replacement rate" $\theta$ that determines the fraction of defaulted obligations $b$ that the lender receives as a transfer from the government, and (ii) a "coverage limit" $\vartheta$ that determines the largest (riskiest) loan that the government will insure. Only loans smaller than, or equal to, $\vartheta$ in size qualify for any compensation; lenders making loans larger than the ceiling receive nothing in the event of default. ${ }^{14}$ Households may borrow more than

household would borrow if asset markets were complete $\left(\beta(1+r)<1\right.$ and $E\left(e_{2}\right)$ significantly larger than $e_{1}$ ). This group is (weakly) harmed by the intertemporal disruptions that default options create; because the two states tomorrow are very similar, the household would either default in both states and thus be unable to borrow at all $(q=0)$, or it would not default in either state and thus care not at all about default options. As a result, the outcome may be worse than if bankruptcy were banned since, in the absence of a default option, feasibility would permit borrowing against the (relatively high) value of $e_{L}$.

For the second type's endowments, three conditions are assumed: (i) the amount of debt that can feasibly be repaid in all states is small (that is, $e_{H}$ is low); (ii) the household will default only in the low state ( $\lambda$ intermediate and $e_{L}$ and $e_{H}$ far apart); and (iii) the household would borrow if asset markets were complete $(\beta(1+r)<1$ and $\left.E\left(e_{2}\right)=e_{1}\right)$. A member of this group can gain from the default option because she actually can borrow more with a bankruptcy option, as she does not intend to repay in the low state; thus, feasibility is limited only by the amount that can be repaid in the high state and additional consumption smoothing is feasible. This is a manifestation of what might be referred to as a "supernatural" debt limit, as opposed to the "natural" debt limit (e.g., Aiyagari 1994): Feasibility involves what can be repaid in the best state instead of the worst.

13 Although not shown in the figure, the typical indifference curve turns upward at very low levels of $b$, but these lie well outside the budget set.

14 This program assumes that the household cannot obtain a qualifying loan of size greater than $\vartheta$ by visiting multiple lenders; that is, we attach the qualification criterion to the borrower, not the lender. 
$\vartheta$, but if they do, the discount on these loans will jump discretely downward as expected rewards to lenders fall discretely due to the "non-conforming" nature of loans exceeding the program limit.

Given that the loan guarantee covers $\theta$ percent of the repayments lost to default for the portion of any loan less than $\vartheta$, competitive pricing of loans for a conforming loan - one with face value $b \leq \vartheta$ must obey

$$
q(b)=\frac{1-\pi(b)}{1+r}+\frac{\pi(b)}{1+r} \theta .
$$

Non-conforming loans are priced exactly as if there was no loan guarantee program in place. In the absence of taxes needed to compensate lenders for default under any guarantee program, it is clear that both types of households would gain from the introduction of loan guarantees. Assuming default probabilities don't change, the guarantee increases the bond price for the first group from 0 to $\frac{\theta}{1+r}$ and for the second group from $\frac{1-p_{L}}{1+r}$ to $\frac{1-p_{L}+p_{L} \theta}{1+r}$. This increase expands the set of feasible consumption paths and raises welfare; default probabilities will not increase if $\theta$ is small enough due to the discreteness of the income process. To illustrate how a loan guarantee works, Figure 1 shows how the pricing function shifts weakly upward, which clearly raises utility because the household is currently constrained and the deadweight loss from default is the same.

\section{Asymmetric Information}

Our analysis has so far focused on limited commitment alone as an impediment to credit access. We now allow for asymmetric information to further hinder lending. To adapt the model to deal with asymmetric information, suppose now that default risk varies according to some characteristic that is not observable to the lender; for concreteness, let there be two such groups, and keep in mind that within each, there are two groups of borrowers with respect to their current cost of default $\lambda$. Private information forces (barring a rich menu of screening contracts) the lender to offer a uniform pricing function to both types of households based on the invariant measure of each type (let $\delta \in(0,1)$ be the measure of the first type); the function is contingent on the costly signal $b$ sent by the household. ${ }^{15}$ The pricing function without

\footnotetext{
${ }^{15}$ We assume that no costless and credible signals are available and that some additional hidden characteristic, such as initial wealth, thwarts the lender's attempts to infer from $b$ the exact value of $\pi$.
} 
the guarantee would be

$$
q(b)=\delta \frac{\widehat{\pi}(b \mid 1)}{1+r}+(1-\delta) \frac{\widehat{\pi}(b \mid 2)}{1+r}
$$

where the hatted variable $\widehat{\pi}$ reflects the fact that under asymmetric information default, probabilities are no longer necessarily known with certainty since the agent who asked for the loan is not necessarily known, in equilibrium, with certainty. Instead, default risk is an imperfect estimate that reflects the uncertainty over which agent-type attempted to take a given loan. For a risk-neutral lender, what is then relevant is the conditional probability of a given loan request having come from either type of borrower (and reflecting the fact that each type will not default with the same probability at any given level of debt). In a more elaborate model (such as the one used later for quantitative analysis), the debt level $b$ would lead lenders to update the estimate of default risk since not all types would find it optimal to issue $b$; in such a case one can think of lenders computing conditional probabilities of the borrower being of a particular type given their requested loan size $b$ (that is, updating $\delta$ ) and using those probabilities to compute default risk. Equilibrium then requires that updated beliefs are consistent with the population of borrowers of a given type issuing $b$.

The "bad" type of borrower - that is, the borrower with the high value of $\widehat{\pi}$-will want to reduce $b$ in order to look more like the good borrower, all things being equal. As discussed more completely in Athreya, Tam, and Young (2012b), pooling is potentially an equilibrium if the pricing function is relatively flat just to the right of the equilibrium choice; in that case, the indifference curves of both types lie above the break-even curve for the lenders so deviations to lower debt levels do not occur. Separating equilibria occur when pricing functions are steep (relative to indifference curves), because then the good type would be better off reducing $b$ while the bad type would not. Loan guarantees reduce the desire of bad types to pool with good types because they break the link between pricing and type; this disincentive is welfareimproving because it improves the allocation of consumption, and so under asymmetric information loan guarantees will have even better welfare properties. But as before, we must consider whether the costs outweigh the gains, and under asymmetric information the costs will increase more than under symmetric information because default is initially lower. Whether the costs or benefits are larger is the main focus of our quantitative model, which we describe in the next section. 


\section{The Irrelevance of Actuarially Fair Loan Guarantees}

In this article, we study fully subsidized guarantees. However, in practice, many loan guarantee schemes ask the borrower to pay the guarantee fee (such as SBA loans and FHA-guaranteed home loans). ${ }^{16}$ An important point we now develop is that any private loan guarantee scheme that is also actuarially fair, and therefore will survive competition, will necessarily be irrelevant.

To see this result, consider a competitive economy in which, notionally, the borrower is obligated to pay the loan guarantee fee, as observed in practice. Let $\tau(b)$ be the insurance premium on a loan with face value (i.e., what is paid outside of default) $b$. Let $q_{f}$ be the reciprocal of the risk-free interest rate, i.e., $q_{f}=1 /(1+r)$, where $r$ is the risk-free rate of interest on savings. As before, let $\pi(b)$ be the probability of default on a loan of size $b$.

A borrower who issues $b$ units of face value then gets, after the insurance payment of $\tau(b), q_{f} b-\tau(b)$ units of resources in period $t$, and is free to default or not in period $t+1$. So what does the guarantee fee have to be? If it is set to break even across all borrowers of the given type of borrower who issued $b$ units of debt, then the premium must be $\tau(b)=\pi(b) b q_{f}$ (the last term appears since the lender will only get paid next period and so must discount), which equals the expected loss on the loan. Therefore, the net resources an agent gets for issuing $b$ units of debt, after paying the loan guarantee premium, is $q_{f} b-\pi(b) b q_{f}$, or $q_{f} b(1-\pi(b))$. But this is exactly the pricing function that would arise in a competitive setting without guarantees.

This result follows naturally from competition between lenders: If the borrower pays the insurance premium and leaves the lender insured, the loan is then risk free to the lender. As a result, a lender can, under competitive conditions, only charge the risk-free rate for the loan. Thus, if loan guarantee schemes are to matter for allocations, they must carry a subsidy with them, such as the one that comes with public provision of the guarantee. This implication is why we study fully subsidized guarantees (no premium). Our approach ensures that guarantees don't merely lead to a reinterpretation of existing contracts, but rather are capable of changing household budget sets. ${ }^{17}$

\footnotetext{
${ }^{16}$ For example, the FHA loan guarantee fee structure is given here: www.sba.gov/community/blogs/community-blogs/small-business-cents/understandingsba-7a-loan-fees.

${ }^{17}$ Our neutrality result holds in the asymmetric information signaling model we study here. Whether it holds in a screening environment (such as Sánchez [2009]) is unclear, since it may be possible to offer $(q, \tau)$ pairs that separate types.
} 
In our quantitative model we study programs that insure only a fraction $\theta$ of loan losses, using tax revenue to fund payments to lenders. The argument here is unchanged - the private sector cannot offer meaningful guarantees for the fraction $1-\theta$ of the loan that the government does not cover.

\section{QUANTITATIVE ANALYSIS}

Given that the implications of guarantees depend on the opposing forces we have isolated above, we now turn to the quantitative analysis of guarantees for consumer credit in order to determine the ultimate effects they may have. The general framework we employ is a standard life-cycle model of consumer debt with default, and aside from the budget-constraint-related complications arising from loan guarantees, the model we use is essentially identical to that of Athreya, Tam, and Young (2012b). ${ }^{18}$

Because the contribution of our article lies in its application of a standard type of model to understand loan guarantees, we relegate the technical description of the model and its parameterization, except for the pricing implications of guarantees, to the Appendix. We will note here only the essential model features, as follows. First, there is a large number (continuum) of households who each live for a finite number of periods. Second, households differ, ex ante, and permanently, in their earnings prospects. This is to reflect differences in the population with respect to educational attainment, and we will therefore allow for three classes of households: those who have not completed high school ("NHS"), those who have completed high school ("HS"), and those who have completed college ("Coll"). Third, households face shocks to their labor productivity throughout life, with shocks having both transitory and persistent components. Fourth, households face the risk of needing to spend suddenly in a manner that is involuntary. These "expenditure shocks" capture the idea that households sometimes face sudden health care expenses or legal obligations that make spending more or less involuntary. Such expenses have been viewed by researchers as relevant in at least a portion of observed default so, for completeness, we include them. Fifth, households have access to credit markets in which they may borrow (and where they will receive guarantees), and may save in a single risk-free asset that earns a constant interest rate.

The features just described lead households in our model to solve a consumption-savings problem over a well-defined life cycle in which

\footnotetext{
${ }^{18}$ Other related work includes Chatterjee et al. (2007) and Livshits, MacGee, and Tertilt (2007), though the former uses an infinite horizon.
} 
Table 1 Model Versus Data

\begin{tabular}{lcc}
\hline \hline & Model & Target/Data \\
Discharge/Income Ratio & 0.2662 & 0.5600 \\
Fraction of Borrowers & 0.1720 & 0.1250 \\
Debt/Income Ratio | NHS & 0.1432 & 0.08 \\
Debt/Income Ratio | HS & 0.1229 & 0.11 \\
Debt/Income Ratio | COLL & 0.0966 & 0.15 \\
Default Rate | NHS & $1.237 \%$ & $1.228 \%$ \\
Default Rate | HS & $1.301 \%$ & $1.314 \%$ \\
Default Rate | COLL & $0.769 \%$ & $0.819 \%$ \\
\hline
\end{tabular}

their productivity has both deterministic and stochastic components. The risks faced by households include, most importantly, those that alter labor earnings, but also those that govern the marginal value of default. Because of default risk, lenders discount household promises according to their estimate of repayment likelihood.

We assume that the economy is small and open, so that the risk-free rate is exogenous. There is a representative firm that takes prices and wages as given, and demands labor as a function of its relative price (the wage). In equilibrium, the wage rate is part of the fixed point with the property that the representative firm's first-order condition governing the level of desired labor input at that wage is equal to household labor supply at that wage.

We will restrict attention throughout to stationary equilibria of the model-i.e., steady states. Stationary equilibria are, as usual, those outcomes where prices and the distribution of households over the state space remain constant under optimal household and firm decisionmaking. More intuitively, aggregate outcomes from our model can be viewed as averages (across households of all ages) for a single large cohort whose members each begin life with zero wealth, draw initial shocks from the unconditional distribution of shocks, and then draw shocks according to the stochastic processes we will specify further below.

To generate predictions from the model, we parameterize the environment to match a set of salient features, as displayed in Table 1. These targets are the ones most relevant for our analysis and collectively cover debt use and default-related features. The main message of Table 1 is that our baseline quantitative accurately captures key features of the data, and hence can be seen as reliable in its implications for the counterfactual exercises we will examine for alternative loan guarantee programs. Table 2 displays the specific parameters used in the quantitative model. We turn next to a description of how, in 
Table 2 Calibration

\begin{tabular}{lllc}
\hline \hline Parameter & Value & Parameter & Value \\
$x_{\text {low }}$ & 0.0000 & $\operatorname{Prob}\left(x_{\text {low }}\right)$ & 0.9244 \\
$x_{\text {median }}$ & 0.0888 & $\operatorname{Prob}\left(x_{\text {median }}\right)$ & 0.0710 \\
$x_{\text {high }}$ & 0.2740 & $\operatorname{Prob}\left(x_{\text {high }}\right)$ & 0.0046 \\
$\lambda_{\text {low }}^{N H}$ & 0.7675 & $\lambda_{\text {high }}^{N H S}$ & 0.9087 \\
$\lambda_{\text {low }}^{H S}$ & 0.7309 & $\lambda_{\text {high }}^{H S}$ & 0.9320 \\
$\lambda_{\text {low }}^{\text {Coll }}$ & 0.7830 & $\lambda_{\text {high }}^{C o l l}$ & 0.9017 \\
$\pi_{H H}^{\lambda}=\pi_{L L}^{\lambda}$ & 0.9636 & $J$ & 65 \\
$j^{*}$ & 45 & $\Lambda$ & 0.0300 \\
$\sigma$ & 2.0000 & $\phi$ & 0.0300 \\
$\alpha$ & 0.3000 & $r$ & 0.0100 \\
\hline
\end{tabular}

the quantitative model, loan guarantees will affect the terms on which credit is available to households.

\section{Loan Pricing and Loan Guarantees}

Loan guarantee regimes are defined by two parameters: the "replacement rate" $\theta$ and the "coverage limit" $\vartheta$. Only loans smaller than $\vartheta$ qualify for any compensation; lenders making loans larger than the ceiling receive nothing in the event of default. ${ }^{19}$ Conditional on default occurring, the lender, having made a loan of qualifying size, will receive partial compensation whereby the fraction $\theta$ will be paid to the lender for each unit of face value. ${ }^{20}$

We focus throughout on competitive lending whereby intermediaries utilize all available information to offer one-period debt contracts with individualized credit pricing that is subject to meeting a zero profit condition. Denote by $I$ the information set of lenders. The information set is, under symmetric information, the entire state vector as understood by the household. In other words, $I$ is the set of items that fully summarizes default risk to a lender for whatever level of borrowing the household requests.

Under asymmetric information, only a subset of these features is known. Specifically, the household's cost of default will not be known to the lender, who must then conjecture it, given the signal embedded

\footnotetext{
19 This restriction seems to be standard practice in markets where some form of loan guarantee program exists. For example, FNMA (Fannie Mae) will not issue guarantees on loans that do not conform to their pre-set standards, which include a restriction on the loan-to-value ratio.

${ }^{20}$ As we noted earlier, qualification actually applies to the total debt of the borrower, not the total loan emanating from any one lender. An implicit assumption is therefore that this debt burden is observable.
} 
in the households requested borrowing amount $b$. Denote this estimate by $\widehat{\pi}(b, I)$. It is the lenders' best estimate of a household's default risk on a debt issuance with face value $b$. Of course, $\widehat{\pi}(b, I)$ is identically zero for positive levels of net worth, and is also equal to 1 for some sufficiently large debt level. Denote by $r$ the exogenous risk-free saving rate. In order to capture the costs associated with lending, we will also assume henceforth that lenders face a constant (i.e., proportional) transaction cost when lending. This implies that $r+\phi$ is the risk-free borrowing rate.

Given the preceding and the loan guarantee program parameters $(\theta, \vartheta)$, the break-even pricing function on loans $(b<0)$ will depend on the size of the loan relative to the guarantee limit $\vartheta$ as follows. Letting, as before, $q(\cdot)$ denote the price, or discount, applied to a bond issuance by a household, we note first that since only loans smaller than the guarantee ceiling entitle lenders to compensation, qualifying loans (those with $b \in(-\vartheta, 0))$ are priced as follows:

$$
q(b, I)=\psi_{j+1 \mid j}\left[\frac{(1-\widehat{\pi}(b, I))}{1+r+\phi}+\frac{\widehat{\pi}(b, I) \theta}{1+r+\phi}\right] \text { if } 0>b \geq-\vartheta .
$$

The first term, $\psi_{j+1 \mid j}$, is new and represents the conditional probability of surviving to age $j+1$ given survival to age $j$. Its presence in the pricing of loans reflects the fact that repayment occurs, if at all, only if the borrower survives. Conditional on survival, the payoff to a loan of face value $b$ will be complete in the event of no default, which occurs with probability $1-\widehat{\pi}(b, I)$, and partial, according to the guarantee, if default occurs. These payoffs are then discounted according to the cost of funds, inclusive of transactions costs, $1+r+\phi$. For any loans exceeding the guarantee qualification threshold, lenders will receive nothing in the event of default. As a result, the preceding zero-profit loan price collapses (the second term goes to zero), yielding the simpler expression

$$
q(b, I)=\psi_{j+1 \mid j}\left[\frac{(1-\widehat{\pi}(b, I))}{1+r+\phi}\right] \text { if } 0>-\vartheta>b .
$$

Lastly, savings are trivial to price, as they carry no transactions costs or default risk. Therefore, for $b \geq 0$, we have

$$
q(b, I)=\frac{1}{1+r} \text { if } b \geq 0 .
$$

As for the fiscal implications of loan guarantees, the budget constraint for the government is straightforward: The flat tax rate on all earnings must be sufficient to make payments to all lenders whose borrowers defaulted on their debts. 


\begin{abstract}
Allocations
We will study four types of allocations. First, we examine our benchmark setting, where information is symmetric and there is no loan guarantee program. Second, we introduce various loan guarantee programs and examine how credit market aggregates, default rates, and welfare are altered. Third, we relax the assumption of symmetric information and study allocations without loan guarantees; in this setting we permit lenders to use all observable characteristics to infer as much as they can about borrowers. Finally, we examine the introduction of loan guarantees into this asymmetric information environment. We will refer to these four allocations as full information without loan guarantees (FI), full information with loan guarantees (FI-LG), asymmetric or "partial" information without loan guarantees (PI), and partial information with guarantees (PI-LG).

To preview the results, we find that introducing a small loan guarantee program into a symmetric information economy (comparing FI with FI-LG) can benefit all households, independent of type, but that increasing generosity quickly eliminates the gains for skilled types. To be clear, our measures of welfare, throughout, will be "ex ante": They are the gains of losses that a household entering the economy at the beginning of its life, i.e., as "newborns", as it were, would obtain. In the environments with asymmetric information (comparing PI to PI-LG), welfare gains are larger for any given generosity, but the same pattern emerges. Thus, a general lesson from these experiments is that loan guarantees are welfare-improving, and in fact can be welfare-improving for all newborns, provided they are not too generous.
\end{abstract}

\title{
Symmetric Information
}

As we noted at the outset, unsecured credit markets are most vital for the consumption smoothing needs of the least wealthy members of any society. This is obvious for any household with liquid wealth, but even those whose wealth is illiquid will, in general, be able to pledge at least a portion of that wealth to obtain credit. Moreover, as we noted, existing work suggests that information asymmetries may not be central, relative to the limited-commitment problem, in explaining current U.S. unsecured credit market activity. We therefore first isolate the role that loan guarantees and limited commitment play in dealing with the effects of such a friction by studying the model under symmetric information. Moreover, since loan guarantee programs require two parameters for their specification, we simplify the results by focusing throughout the analysis - and unless otherwise stated - on the case 
Table 3 Aggregate Effects of Loan Guarantee Program

\begin{tabular}{lccccc}
\hline \multicolumn{2}{c}{$\theta=0.50$} \\
$\vartheta$ & 0.00 & 0.10 & 0.30 & 0.60 & 0.70 \\
$\tau_{2}$ & 0.0000 & 0.0005 & 0.0174 & 0.0531 & 0.0664 \\
Discharge/Income Ratio & 0.2662 & 0.2691 & 0.5430 & 0.9907 & 1.1172 \\
Fraction of Borrowers & 0.1720 & 0.2039 & 0.2400 & 0.4023 & 0.4466 \\
Debt/Income Ratio | NHS & 0.1432 & 0.1648 & 0.4765 & 0.6562 & 0.7118 \\
Debt/Income Ratio | HS & 0.1229 & 0.1372 & 0.3707 & 0.5369 & 0.5934 \\
Debt/Income Ratio | COLL & 0.0966 & 0.1140 & 0.2532 & 0.3858 & 0.4124 \\
Default Rate | NHS & $1.237 \%$ & $1.768 \%$ & $11.651 \%$ & $19.691 \%$ & $20.877 \%$ \\
Default Rate | HS & $1.301 \%$ & $1.751 \%$ & $11.658 \%$ & $16.609 \%$ & $17.836 \%$ \\
Default Rate | COLL & $0.769 \%$ & $0.987 \%$ & $5.668 \%$ & $11.569 \%$ & $13.100 \%$ \\
\hline
\end{tabular}

where the replacement rate is set to cover 50 percent of lender losses, i.e., $\theta=0.5$.

\section{Allocations and Pricing}

Our first main result is that loan guarantees are powerful tools in altering the use of unsecured credit. In Table 3, we see that as we move away from the case with no loan guarantees $(\vartheta=0)$, equilibrium borrowing rises for all households and the increase in debt is nonlinear. In particular, for small qualifying loan sizes (e.g., $\vartheta=0.1$, or $\$ 4,000$ ), allocations are fairly similar to a setting with no guarantees. In large part, this similarity reflects the presence of bankruptcy costs that serve as a form of implicit collateral. In particular, the fixed cost component of bankruptcy $(\Lambda)$ will ensure the existence of a region of risk-free debt. Therefore, under a small qualifying loan size, few individuals will see their access to credit substantially altered; in fact, setting $\vartheta<-\Lambda$ would have no effect on credit, since those loans are always risk free. Once the qualifying loan size grows large enough to make large loans "cheap" relative to default risk, matters are different. The compensation to lenders for default disproportionately subsidizes large loans and thereby generates the significant additional default seen in Table 3.

The differential distortion to loan pricing is displayed in Figure 2, and our model suggests that this feature helps account for the striking distributional consequences seen in Table 3. In particular, borrowing behavior changes in different ways across the education groups. Relative to income, debt rises by far the most for the least skilled (NHS) households. The differential increase in debt relative to income for the lowest skilled is also reflected in the disproportionate rise in bankruptcy rates within this group. While remaining modest under small qualifying loan ceilings, more generous ceilings create greatly increased 


\section{Figure 2 Pricing Functions with and without Loan Guarantees}

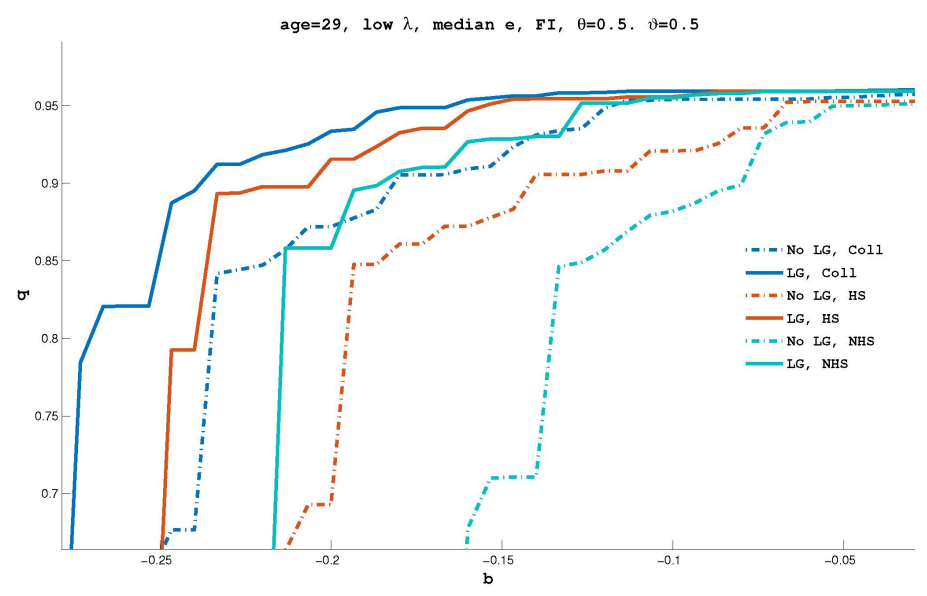

default rates. The preceding suggests in part that the pricing of debt is a meaningful barrier to nearly all households, but especially NHS households. An additional force at work is that high-skilled households have less reason to use unsecured credit beyond early life. As a result, any distortion in the pricing of debt will affect them less than their NHS counterparts. In particular, all NHS households who have income below their age-specific mean will find "artificially" cheap credit useful, while the well-educated, many of whom wish to save less for precautionary reasons (i.e., to hedge against possible bad outcome for income in the future) and more for life-cycle (keeping consumption stable as household age) reasons, will be less sensitive to credit conditions. The latter insensitivity arises from the fact that an individual or household with a pronounced hump in their average earnings shown in Figure 3 will wish to save less or borrow when young, and save in the peak earnings years in order to have a comfortable retirement period (which the model captures by making households incapable of working beyond a certain age). Lastly, under high ceilings for qualifying loan guarantees, the high tax rate will also meaningfully compress the intertemporal profile of earnings, and therefore attenuate the incentives of the skilled to borrow for pure life-cycle smoothing. This will make loan guarantees even less valuable. 
Figure 3 Efficiency Units of Labor

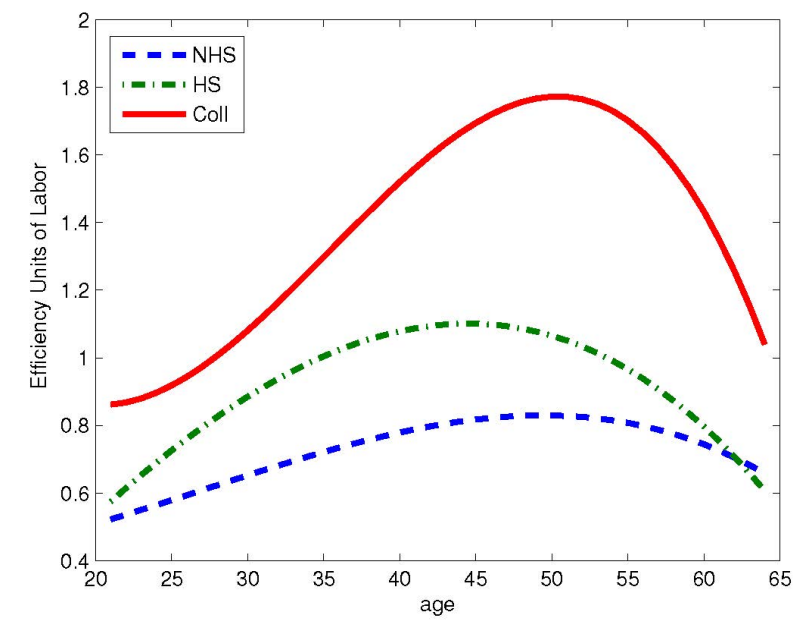

\section{Welfare}

Having shown results suggesting that loan guarantees will likely have sizeable and nonlinear effects on credit use and default, we now turn to the issue that motivated us at the outset: Can loan guarantees, by breaking the link between credit risk and loan pricing, improve welfare? And if so, for whom? Our metric for measuring welfare is standard: it is the change to consumption at all dates and states needed to make the household indifferent, in terms of ex ante expected utility, between the benchmark economy and the one with loan guarantees.

A fact that will be important for welfare is that households in our economy who borrow are always constrained. Figure 4 plots indifference curves in $(b, q)$ space along with the zero-profit pricing function; the optimal amount of borrowing and the resulting price lies where the highest indifference curve intersects this zero-profit curve. At this point, the slope of the indifference curve is strictly smaller than the slope of the pricing function (which is infinite). This implies that borrowing more is desirable at the current interest rate, but the increase in the default rate that a marginal increase in $b$ would generate means that lenders must charge a higher rate. As a result, by reducing the slope of the pricing function at the optimal point, loan guarantees can improve utility at the margin. What we are contemplating, however, are not 
Figure 4 Optimal Choice of Borrowing

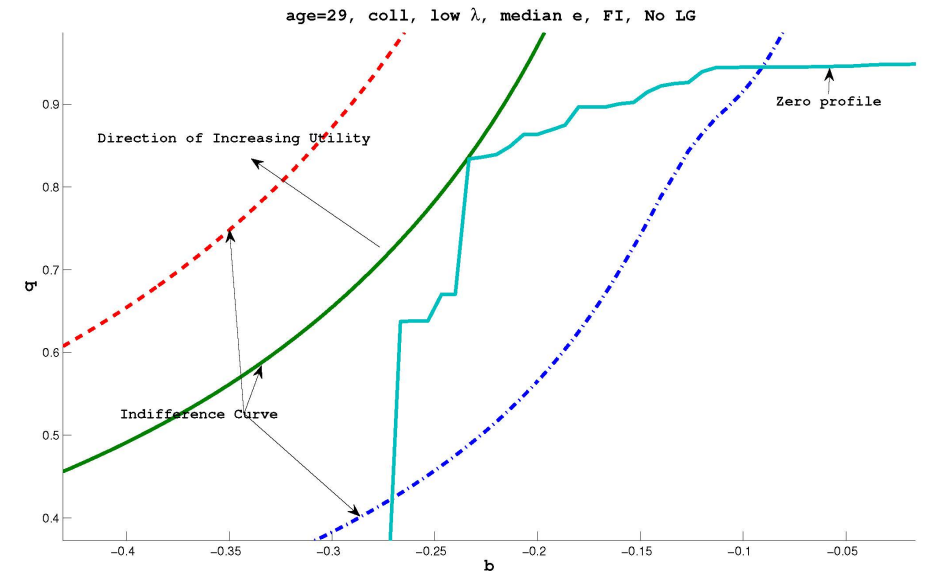

marginal changes; thus, whether a discrete change is welfare-improving is a quantitative question.

We see first, from Table 3, that more generous loan guarantees come with higher taxes, and that the taxes also naturally reflect the nonlinearity in household borrowing and default behavior. However, not all households pay the same amount in taxes, and, as we noted, proportional taxes - which are used here - will by themselves provide some risk-sharing benefits. Moreover, the loan guarantee may allow for an effective form of insurance for some households, especially the low-skilled. The transfers from loan guarantees come "at the right time" for households, but require households to pay a cost, which, intuitively, is akin to a deductible on an insurance policy. Therefore, while households pay more in taxes under a generous loan guarantee scheme, they also receive transfers in a manner that is effective in providing insurance.

Turning to welfare in Table 4, we see that this is precisely what is at work. In this table a positive value indicates a gain to welfare from moving to loan guarantees, and vice versa. In particular, we see that generous loan guarantee schemes mainly represent transfers to the very unskilled. These are, in turn, the groups with the most to gain from improved credit access. As a result, the most skilled households lose in welfare terms from any qualifying loan sizes in excess of approximately $\$ 4,000(\vartheta=0.1)$. Conversely, HS households continue to gain, and gain substantially in welfare terms, from loan guarantees of up to 
Table 4 Optimal Generosity of Loan Guarantee Program

\begin{tabular}{lccc}
\hline & $\theta=0.50$ & & \\
& COLL & HS & NHS \\
$\vartheta=0.00 \rightarrow \vartheta=0.10$ & $0.02 \%$ & $0.08 \%$ & $0.13 \%$ \\
$\vartheta=0.00 \rightarrow \vartheta=0.20$ & $-0.24 \%$ & $0.20 \%$ & $0.22 \%$ \\
$\vartheta=0.00 \rightarrow \vartheta=0.30$ & $-1.41 \%$ & $0.27 \%$ & $0.39 \%$ \\
$\vartheta=0.00 \rightarrow \vartheta=0.40$ & $-1.60 \%$ & $0.19 \%$ & $0.78 \%$ \\
$\vartheta=0.00 \rightarrow \vartheta=0.50$ & $-2.24 \%$ & $-0.11 \%$ & $1.06 \%$ \\
$\vartheta=0.00 \rightarrow \vartheta=0.60$ & $-2.84 \%$ & $-0.35 \%$ & $1.26 \%$ \\
$\vartheta=0.00 \rightarrow \vartheta=0.70$ & $-3.60 \%$ & $-0.44 \%$ & $1.02 \%$ \\
\hline
\end{tabular}

$\$ 16,000(\vartheta=0.4)$. Most strikingly, NHS households gain for very large loan guarantee levels, even to levels exceeding their mean income level. In summary, our results suggest that modest loan guarantee programs can improve welfare for all households, even those households who likely will pay the bulk of the taxes needed to finance them. However, our model also suggests that qualifying loan size is likely to be quite important in determining whether a particular guarantee program serves all households or instead functions as a very significant redistributive mechanism. In the absence of definitive means for detecting the sensitivity of aggregate credit use and default to the size of qualifying loans, instituting a program that is too generous will lead to significant welfare losses for some groups.

Where do the welfare gains come from? Table 5 shows mean consumption and decomposes the variance of consumption into two moments: the variance of mean consumption by age, a measure of intertemporal consumption smoothing, and the mean of consumption variance by age, a measure of intratemporal consumption smoothing. ${ }^{21}$ What we mean here is the following. "Intertemporal" smoothing refers to how much variation of consumption or living standards individuals experience. We measure it by calculating how much average consumption varies over the life cycle, and we average consumption as a natural measure of what the individual can expect at any given age. This is an intuitive measure of consumption smoothing through time: If the variance of average consumption over the life cycle were high, this would mean that young and old households were, on average, consuming quite different amounts. As for "intratemporal" smoothing, our measure answers the question of how much variability there is among households of any given age, when averaged across individuals of all ages. In other

\footnotetext{
${ }^{21}$ Specifically, we use the decomposition: $\operatorname{var}(\log (c))=\operatorname{var}(\mathrm{E}[\log (c) \mid j])+$ $\mathrm{E}[\operatorname{var}(\log (c) \mid j)]$.
} 
Table 5 Distribution of Consumption

\begin{tabular}{|c|c|c|c|c|}
\hline & $\mathrm{E}(c)$ & $\begin{array}{r}\operatorname{var}(\log (c)) \\
\text { Aggre }\end{array}$ & $\mathrm{E}(\operatorname{var}(\log (c) \mid a g e))$ & $\operatorname{var}(\mathrm{E}(\log (c) \mid a g e))$ \\
\hline NO LG & 0.8455 & 0.1894 & 0.1671 & 0.0223 \\
\hline $\mathrm{LG} \vartheta=0.5, \theta=0.5$ & 0.8016 & $\begin{array}{r}0.1977 \\
\text { Coll }\end{array}$ & 0.1755 & 0.0222 \\
\hline $\mathrm{NO} \mathrm{LG}$ & 1.0918 & 0.1776 & 0.1293 & 0.0481 \\
\hline $\mathrm{LG} \vartheta=0.5, \theta=0.5$ & 1.0521 & $\begin{array}{l}0.3874 \\
\text { High S }\end{array}$ & hool & 0.0520 \\
\hline NO LG & 0.7767 & 0.2279 & 0.1907 & 0.0372 \\
\hline $\mathrm{LG} \vartheta=0.5, \theta=0.5$ & 0.7575 & $\begin{array}{l}0.3926 \\
\text { Non-Higl }\end{array}$ & School 0.3749 & 0.0180 \\
\hline NO LG & 0.6579 & 0.2807 & 0.2582 & 0.0225 \\
\hline $\mathrm{LG} \vartheta=0.5, \theta=0.5$ & 0.6514 & 0.3932 & 0.3849 & 0.0083 \\
\hline
\end{tabular}

words, what is the average variability of consumption that one would expect to observe if one drew a sample of households of any given age? The decomposition of total variance into these components is a complete one: Together they account for the total variance of consumption in the model (and this is due to a simple statistical fact known as the "law of total variance").

Loan guarantees reduce average consumption due to the combination of higher taxes, more borrowing, and more frequent default. The gain comes through a better distribution of consumption over the life cycle. We see here that this gain is driven entirely by a reduction in the intertemporal dimension as intratemporal consumption volatility actually increases.

We note here that our welfare results differ significantly from those in Athreya et al. (2012), where the role of the out-of-pocket costs of default, $\Lambda$, in restricting access to bankruptcy is explored. High values of $\Lambda$ restrict access to bankruptcy to high income types (who typically do not want to default), and in a wide range of models the optimal value (from an ex ante perspective) is infinite for all types; that is, from the perspective of a newborn household, permitting any bankruptcy in equilibrium is suboptimal. The largest gains are experienced by the college types, because they have the strongest demand to borrow for purely intertemporal reasons (i.e., reasons unrelated to the effects of uncertainty) and this demand is thwarted by risk-based pricing. There are a number of reasons to view that result as impractical from a policy 
Table 6 Welfare Decomposition, Symmetric Information

\begin{tabular}{cccc}
\hline$\vartheta=0.5, \theta=0.50$ & & \\
& COLL & HS & NHS \\
$\left(q^{N L G}, \tau_{2}=0.0\right) \rightarrow\left(q^{L G}, \tau_{2}=0.0\right)$ & $4.86 \%$ & $8.30 \%$ & $10.69 \%$ \\
$\left(q^{L G}, \tau_{2}=0.0\right) \rightarrow\left(q^{L G}, \tau_{2}=0.0386\right)$ & $-6.74 \%$ & $-7.76 \%$ & $-8.69 \%$ \\
\hline
\end{tabular}

perspective. Loan guarantees, in contrast, are clearly policy-feasible and benefit the least-skilled more than the more-skilled. ${ }^{22}$

\section{Decomposing the Effect of Taxes on Welfare}

In this subsection we decompose the net effect of the loan guarantee program. We consider two experiments, presented in Table 6, where we ask how welfare changes if we confront an individual with the pricing emerging from the presence of a loan guarantee, with and without the taxes needed to finance the program. Starting in the top row of Table 6 we display the effect of a move from the benchmark setting to one in which a tax-free loan guarantee is provided. Welfare increases quite substantially, again by least for the skilled and by most for the unskilled. Since their income profile is flat, the NHS households experience the largest gain because they use unsecured debt over most of their life cycle. By contrast, the more-skilled types decrease unsecured borrowing as they age (see Figure 5).

Turning next to the bottom row of Table 6 , we present the welfare implications of a move from a setting with a tax-free loan guarantee to one where, including taxes, the program must now break even. As seen earlier (Table 5), once taxes are imposed only the unskilled benefit from a program this generous, and they lose proportionally more from taxes than do the college types. Why are the costs of a small tax so large in this model? With taxes, permanent income is reduced, leaving households more exposed to the expenditure shock. As a result, they "involuntarily" default more frequently, leading to more deadweight loss and a much larger welfare loss than one would expect from a tax of less than 4 percent. Due to the accumulation pattern of net worth,

\footnotetext{
22 Dávila et al. (2012) shows that utilitarian constrained efficient allocations in a model with uninsurable idiosyncratic shocks are skewed toward improving the welfare of "consumption-poor" households (since they have higher marginal utility). While we do not attempt to characterize constrained efficient allocations here, it seems clear that this intuition would apply-thus, policies that raise the utility of the least-skilled would seem to be preferable from a social welfare perspective.
} 
Figure 5 Net Worth Over the Life Cycle

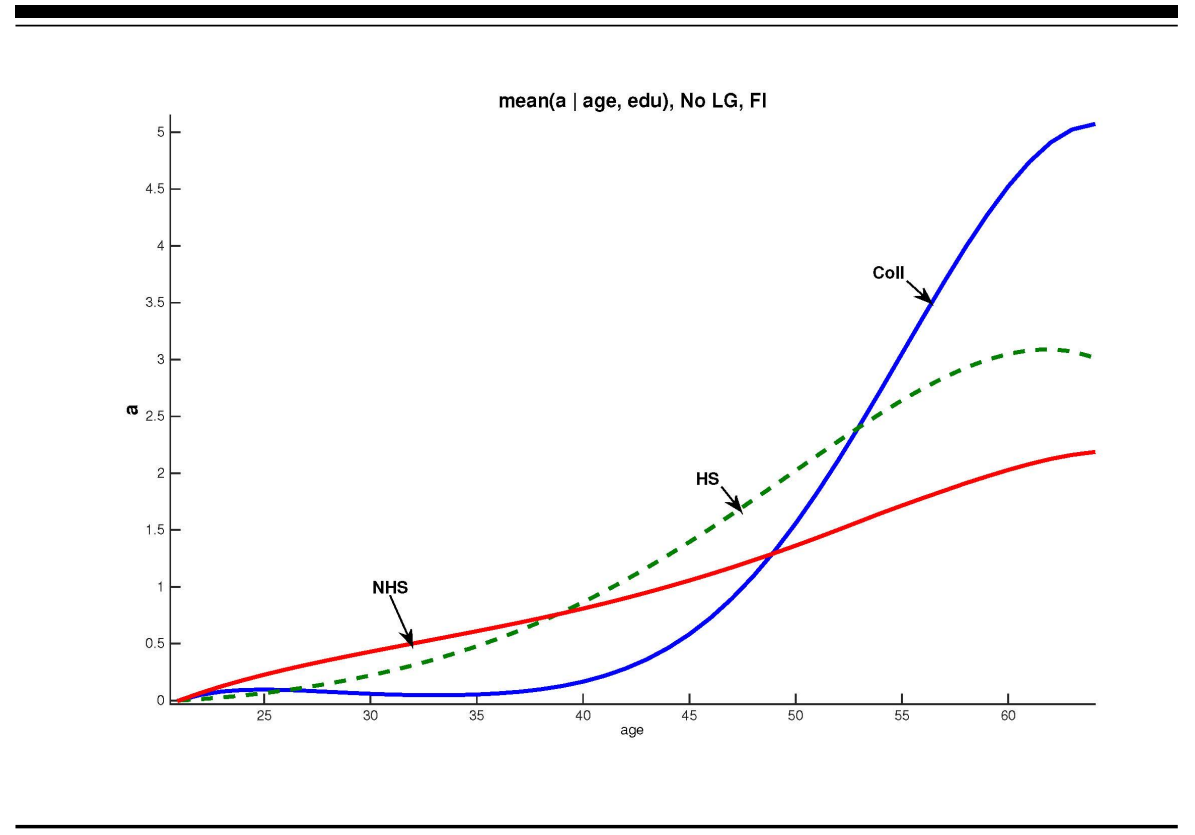

on average NHS households are more exposed to this risk (again, see Figure 5).

Table 7 decomposes the costs of the program by type. The loan guarantee program transfers resources along two dimensions. First, loan guarantees transfer resources from skilled households to less-skilled; college types pay into the program, via taxes, significantly more than they collect in terms of lower interest rates. Second, loan guarantees transfer resources from individuals who pose little default risk (those with low $\lambda$ ) to those with a high value for $\lambda$, as the latter pose more default risk, all else equal. This transfer occurs because the high-risk types would pay substantially higher interest rates without intervention and therefore gain a lot from the program.

\section{Asymmetric Information}

Returning to the problem noted at the outset of the previous subsection, recall that the cost of limited access to unsecured credit is likely largest for the least wealthy. This is particularly likely to be true in a society that lacks the information storage, sharing, and data analysis available in developed nations to effectively identify credit risk at the time of loan origination (and then update it regularly). As a first step 
Table 7 Distribution of Net Costs Paid by Type

\begin{tabular}{|c|c|c|c|c|}
\hline \multirow[b]{3}{*}{ Coll } & \multicolumn{3}{|c|}{$\begin{array}{l}\vartheta=0.50, \theta=0.50, \text { FI } \\
\text { High } \lambda\end{array}$} & Low $\lambda$ \\
\hline & Taxes & Transfer & Taxes & Transfer \\
\hline & 0.1366 & 0.1050 & 0.1366 & 0.0384 \\
\hline HS & 0.2995 & 0.5082 & 0.2995 & 0.1512 \\
\hline \multirow[t]{3}{*}{ NHS } & 0.0639 & 0.1333 & 0.0639 & 0.0639 \\
\hline & High $\lambda$ & $.50, \theta=0$ & \multicolumn{2}{|c|}{ Low $\lambda$} \\
\hline & Taxes & Transfer & Taxes & Transfer \\
\hline Coll & 0.1366 & 0.1155 & 0.1366 & 0.0341 \\
\hline $\mathrm{HS}$ & 0.2995 & 0.4971 & 0.2995 & 0.1239 \\
\hline NHS & 0.0639 & 0.1711 & 0.0639 & 0.0583 \\
\hline
\end{tabular}

in getting a sense of the quantitative potential of loan guarantees to alter outcomes in such settings, we now study stationary equilibria of our model under asymmetric information.

To remind the reader, in our economy, asymmetric information will mean that the borrower will have characteristics that are not observable to the lender; specifically, we assume neither current stigma, $\lambda$, nor current net worth, $a$, can be directly observed. However, any information about these variables that can be inferred from the observable components of the state vector, as well as from the desired borrowing level, $b$, is available to the lender. ${ }^{23}$ We focus on two representative examples: one that represents a relatively modest loan guarantee program and results in welfare gains for all types under symmetric information $(\theta=0.1$ and $\vartheta=0.1)$, and one that is more generous and reduces the welfare of college-educated types $(\theta=0.5$ and $\vartheta=0.4)$. Our key finding is that the presence of asymmetric information will increase the gains available from loan guarantees, no matter how generous.

\section{Allocations and Pricing}

We first compare outcomes in the FI and PI economies. Table 8 shows that a move from symmetric to asymmetric information has the following effects. First, default falls for all types, and default skews more strongly toward the high $\lambda$ type; these individuals are treated relatively better under asymmetric information, since they get terms that reflect the average default risk instead of their own, and therefore end up

\footnotetext{
${ }^{23}$ We assume that credit markets are anonymous, so that past borrowing is also not observable to the current lender. In Athreya, Tam, and Young (2012b) we introduce a flag that tracks whether a household is likely to have recently defaulted. Due to computational considerations we do not examine this case here.
} 
Table 8 Aggregate Effects of Loan Guarantees-Asymmetric Information

\begin{tabular}{lcccc}
\hline \multicolumn{2}{c}{$\vartheta=0.40$} & \multicolumn{2}{c}{ PI } \\
\multicolumn{2}{c}{ FI } & \multicolumn{2}{c}{0.0000} & 0.5000 \\
$\theta=$ & 0.0000 & 0.5000 & 0.0000 & 0.0196 \\
$\tau_{2}$ & 0.0000 & 0.0245 & 0.2021 & 0.6497 \\
Discharge/Income Ratio & 0.2662 & 0.6965 & 0.1614 & 0.3036 \\
Fraction of Borrowers & 0.1720 & 0.3109 & 0.1209 & 0.4762 \\
Debt/Income Ratio | NHS & 0.1432 & 0.4880 & 0.0909 & 0.3755 \\
Debt/Income Ratio | HS & 0.1229 & 0.3897 & 0.0801 & 0.2389 \\
Debt/Income Ratio | COLL & 0.0966 & 0.2691 & $0.956 \%$ & $12.704 \%$ \\
Default Rate | NHS & $1.237 \%$ & $13.170 \%$ & $0.957 \%$ & $11.407 \%$ \\
Default Rate | HS & $1.301 \%$ & $12.310 \%$ & $0.658 \%$ & $5.412 \%$ \\
Default Rate | COLL & $0.769 \%$ & $6.304 \%$ & & \\
\hline
\end{tabular}

borrowing amounts that induce relatively high default rates. Second, overall the credit market shrinks, in the sense that we observe fewer borrowers (of each type) and lower discharged debt aggregates.

Figure 6 shows that pricing is significantly worse for the high $\lambda$ (low bankruptcy cost) borrower and better for the low $\lambda$ borrower. Under asymmetric information, the two types will be pooled together, so that the default premium at a given debt level reflects the average default risk. The result is that good borrowers face significantly tighter credit limits and higher interest rates, while bad borrowers face the same credit limit but lower interest rates. The shift in pricing accounts for the smaller credit market size.

Third, as noted at the outset, our model features expenditure shocks. These shocks take on a larger role in defaults under asymmetric information (see Table 9). With tighter credit limits, big expenditure shocks that hit when the household is young are hard to smooth, since income is relatively low. The result is that essentially all defaults are done by households who have received an expenditure shock, despite this group being only 7.56 percent of the population. Information has less of an impact on these defaults, since they are defaults on debt that has been acquired involuntarily.

We now turn to the effects of loan guarantees under asymmetric information. Table 8 shows that the change induced by the introduction of the particular program is larger for all credit market aggregates under asymmetric information, with the exception of the debt-to-income ratio for college-educated households (in which case it is of only slightly smaller magnitude). Figure 7 shows the increased access to credit that guarantees provide in these two cases. Note that the increase in the default rate is smaller under asymmetric information for every 


\section{Figure 6 Pricing with Symmetric and Asymmetric Information}

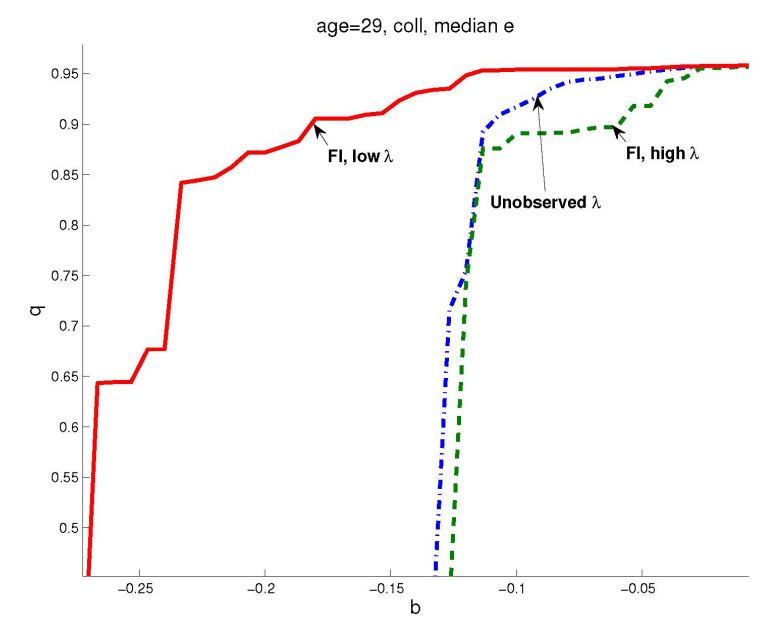

education group. As a result, the taxes required to finance the program are lower than under symmetric information.

\section{Welfare}

Table 10 displays the welfare effects of two different loan guarantee programs. Relative to the symmetric information case, loan guarantees are uniformly better when information is asymmetric; this result holds for every case we have computed. The larger gain is partly due to the lower tax burden required in the asymmetric information cases and partly due to the severe pricing distortion caused by asymmetric information evident in Figure 6.

To more directly describe the transfers between agents induced by loan guarantees, Table 7 collects the proportion of costs paid by each group. Now the loan guarantee program subsidizes the high $\lambda$ (low stigma cost) types much more than under symmetric information. This result is exactly what we would expect, given that this type is receiving better credit terms under asymmetric information.

\section{Targeted Loan Guarantees}

Our results suggest that loan guarantees have the potential to become primarily a means of transferring resources from the rich to the poor. 
Table 9 Distribution of Default by State

\begin{tabular}{|c|c|c|c|c|}
\hline \multirow{5}{*}{$\begin{array}{l}\text { Low } x \\
\text { Median } x \\
\text { High } x\end{array}$} & \multicolumn{2}{|c|}{ FI } & \multicolumn{2}{|c|}{ PI } \\
\hline & High $\lambda$ & Low $\lambda$ & High $\lambda$ & Low $\lambda$ \\
\hline & 0.2315 & 0.0092 & 0.0089 & 0.0000 \\
\hline & 0.5811 & 0.0670 & 0.8033 & 0.0399 \\
\hline & 0.0666 & 0.0446 & 0.0890 & 0.0588 \\
\hline
\end{tabular}

Moreover, our findings suggest that they may also lower welfare, often of all types of agents, unless their generosity is modest. In our results, default is disproportionately driven by those who have received an expenditure shock. A natural question therefore is whether the benefits of loan guarantees discussed at the outset can be preserved by limiting compensation to lenders only when a borrower has suffered such a shock. Expenditure shocks represent large increases in debts that are rare and involuntarily acquired. As a result, a policy of guaranteeing loans only under these conditions is unlikely to alter loan pricing substantially (since these states are rare) but may substantially aid households who find themselves in those rare states. Moreover, targeted guarantees are unlikely to induce significant additional deadweight loss because the default decision is more frequently heavily influenced by expenditure shocks, which again, are rare.

To investigate this question, we study a case where $\vartheta=0.50$ and $\theta=0.50$, but where lenders only receive compensation in the event that a bankruptcy coincides with a positive expenditure shock $(x>$ $0)$. Table 11 shows that all groups gain from the introduction of a loan guarantee program restricted in this manner. As before, the NHS households gain most and the highly skilled gain the least. Nonetheless, the ability of the conditionality of the program to overturn what was initially a very large welfare loss to the skilled into a gain is striking. ${ }^{24}$

To see the effect on aggregates more generally, we turn to Table 12. It is immediately clear that the tax rate needed to sustain the restricted loan guarantee program is very small relative to the unrestricted case, even though the debt discharged in bankruptcy is similar to the unrestricted guarantee case. Nonetheless, the overall level of debt responds to the restricted guarantee far more modestly than the unrestricted case. For example, under restricted guarantees, the mean

\footnotetext{
${ }^{24}$ We are implicitly assuming that expenditure shocks are likely to be easy to observe; we doubt that agents could easily hide one from the government, given the size and nature of these shocks. Our calibration, as noted above, equates $x$ to a combination of medical and legal bills plus unplanned family costs; these expenses should be relatively easy to monitor in practice.
} 


\section{Figure 7 Pricing with Loan Guarantee, Symmetric versus Asymmetric Information}

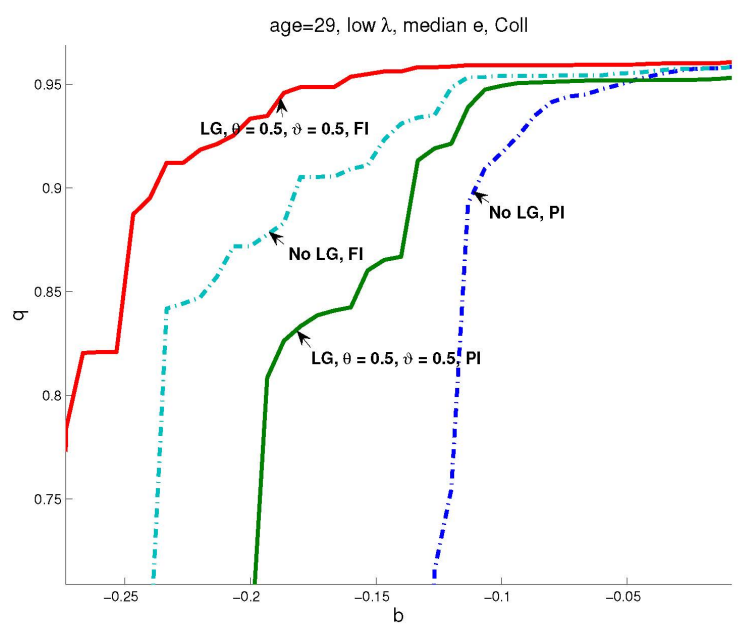

debt-to-income ratio among high-school educated borrowers is less than half that under unrestricted guarantees $(0.2256$ versus 0.4707$)$. The central reason for the low tax rate is that the default rate responds by far less than with an unrestricted program, even though borrowing does increase nontrivially, relative to the benchmark case. Under restricted guarantees, the bankruptcy rate roughly doubles, while the unrestricted program implies a nearly ten-fold increase.

\section{DISCUSSION}

We have made a few assumptions in our model that require some additional discussion. First, we have assumed that factor prices are fixed. General equilibrium calculations would imply higher $r$ and lower $W$ would prevail under loan guarantee systems, since they produce more borrowing and less aggregate wealth (as well as increasing the amount of transactions costs that works like a reduction in aggregate supply of goods). Factor price movements of this sort are likely to make the welfare costs larger (gains smaller), since the higher risk-free interest rate would make borrowing more costly and the lower wages would reduce mean consumption. Despite these effects, we choose to abstract from equilibrium pricing because it is well known that income processes representative of the vast majority of households will, in environments 
Table 10 Welfare Effects of Loan Guarantees

\begin{tabular}{lccc}
\hline & COLL & HS & NHS \\
NO LG $\rightarrow \theta=0.50, \vartheta=0.40$, FI & $-1.60 \%$ & $0.19 \%$ & $0.78 \%$ \\
NO LG $\rightarrow \theta=0.50, \vartheta=0.40$, PI & $-1.02 \%$ & $0.98 \%$ & $1.59 \%$ \\
NO LG $\rightarrow \theta=0.10, \vartheta=0.10$, FI & $0.01 \%$ & $0.02 \%$ & $0.03 \%$ \\
NO LG $\rightarrow \theta=0.10, \vartheta=0.10$, PI & $0.04 \%$ & $0.08 \%$ & $0.11 \%$ \\
\hline
\end{tabular}

such as ours, produce less wealth concentration than observed (see Castaneda, Díaz-Giménez, and Ríos-Rull 2003), meaning that the mean wealth position will be too similar to the median, implying larger factor price changes than would occur if the distribution of wealth were matched. Given the immense computational burden that matching the U.S. Gini coefficient of wealth would impose on our OLG setup, and given that the factor price adjustments should be small, we feel justified in ignoring them. ${ }^{25}$

Second, we have financed the program using proportional labor income taxes. An obvious alternative would be to finance the program using progressive income taxes, where high income (college) types would pay higher marginal tax rates. This approach would increase the gains to the NHS types, who already gain substantially, and reduce (or even eliminate) any gains to college types. We expect a similar result from capital income taxation as well, since it will tend to tax the wealthier college types more heavily. In contrast, a regressive income tax would imply the types who benefit the most, the NHS, would pay a higher marginal tax rate. Regressive tax systems seem unlikely to be implemented on equity grounds, even if they are welfare-improving within a specific model. We could also introduce separate programs for each education group, so that the cross-subsidization that makes the program so attractive to NHS types would be eliminated; we conjecture that this case would result in larger gains for college types and smaller for NHS types.

Third, there is a conceptual issue of the right benchmark allocation. The U.S. corporate income tax rate is 35 percent and banks are permitted to deduct losses due to nonperforming loans from their taxable income. As a result, it may be that the appropriate benchmark is a case where the loan guarantee program is not zero, but rather has a large value of $\vartheta$ and $\theta=0.35$. We can of course easily express the welfare

\footnotetext{
${ }^{25}$ In Chatterjee et al. (2007), the model is calibrated to the U.S. distribution of wealth; the resulting effects of an endogenous risk-free rate are quantitatively unimportant.
} 
Table 11 Welfare Effects of Restricted Loan Guarantees

\begin{tabular}{lrcc}
\hline \hline & & & \\
& $\vartheta=0.5, \theta=0.50$ & & NHS \\
NO LG $\rightarrow$ Restricted LG & COLL & HS & $0.99 \%$ \\
Restricted LG $\rightarrow$ Unrestricted LG & $0.40 \%$ & $0.77 \%$ & $-0.07 \%$ \\
\hline
\end{tabular}

gains relative to this benchmark instead; a more detailed investigation of this issue is part of ongoing work.

There are some natural extensions of our model that seem useful to pursue. Given our results regarding the effect of loan guarantees to redistribute toward the unskilled from the skilled, it would be productive to know if the least skilled, for example, would benefit from a loan guarantee program that was required for self-financing via taxes on only the unskilled. Such an extension would be along the lines explored in Gale (1991), who studies targeted loan guarantees designed to facilitate credit access for certain identifiable subpopulations (such as minority borrowers). Targeted programs would be related to the regulations we mentioned earlier that require certain characteristics not be reflected in credit terms; exactly how the dual goals of encouraging access to these groups without allowing their characteristics to alter credit terms would affect welfare is unknown and worth studying. It would also be straightforward to investigate loans targeted to individual borrowers who are deemed constrained by competitive lenders. ${ }^{26}$ In our model, since borrowers are at a "cliff" in the pricing function, they would benefit from government loans at their existing interest rate, provided the tax costs are not "too high."

Also, our work is a step in the direction that, in the future, will allow us to analyze the role of guarantees for mortgage lending. However, the central role of aggregate risk in driving home-loan default makes a full quantitative analysis that satisfactorily incorporates the forces we do allow for here - asymmetric information and limited commitmentcurrently infeasible. But we note that such a model would have the same fundamental structure as that developed here.

\section{CONCLUDING REMARKS}

A significant share of the U.S. population appears credit constrained. These households usually lack collateral and must therefore rely on the unsecured credit market to help them smooth consumption in the

\footnotetext{
${ }^{26}$ A stylized approach to this is taken in Smith and Stutzer (1989).
} 
Table 12 Aggregate Effects of Restricted Loan Guarantees

\begin{tabular}{lccc}
\hline & $\vartheta=0.50$ & & \\
$\theta=$ & 0.00 & 0.50 & 0.50 \\
& No LG & Restricted LG & Unrestricted LG \\
$\tau_{L G}$ & 0.0000 & 0.0004 & 0.0386 \\
Discharge/Income Ratio & 0.2662 & 0.7208 & 0.8657 \\
Fraction of Borrowers & 0.1720 & 0.2408 & 0.3527 \\
Debt/Income Ratio | NHS & 0.1432 & 0.2649 & 0.5738 \\
Debt/Income Ratio | HS & 0.1229 & 0.2256 & 0.4707 \\
Debt/Income Ratio | COLL & 0.0966 & 0.1681 & 0.3285 \\
Default Rate | NHS & $1.237 \%$ & $2.755 \%$ & $16.797 \%$ \\
Default Rate | HS & $1.301 \%$ & $2.586 \%$ & $14.619 \%$ \\
Default Rate | COLL & $0.769 \%$ & $1.643 \%$ & $9.072 \%$ \\
\hline
\end{tabular}

face of life-cycle and shock-related movements in income. However, the unsecured credit market in the United States appears significantly impeded by forces that keep the costs of unsecured debt default low, and thereby make lending risky and, hence, expensive. Perhaps the most widely used route to increase credit flows to target groups is via the use of loan guarantees whereby public funds defray private lenders' losses from default. Aside from their direct effects on credit access and pricing, guarantees are likely to be particularly useful in unsecured credit markets given limitations on the ability of policies to directly influence borrowers' default incentives. In this article, we assess the consequences of extending loan guarantees to unsecured consumer lending to improve allocations.

Our article attempts to quantify the impact of loan guarantees in a model that incorporates both meaningful private information and a limited commitment problem into a rich life-cycle model of consumption and savings. Our quantitative analysis focuses on evaluating the impact of introducing loan guarantees into unsecured consumer credit markets. These markets have large consequences for household welfare because they influence the limits on smoothing faced by some of the least-equipped subgroups in society, particularly the young and the unlucky.

Our calculations suggest first that, under symmetric information, loan guarantees can actually improve the ex ante welfare of all households if they are not too generous (meaning only small loans qualify). This welfare gain is disproportionately experienced by low-skilled households who face flat average income paths and relatively large shocks. Indeed, such households gain from very generous programs, but higher-skilled types rapidly begin to experience welfare losses as loan guarantees are made more generous. These results arise because 
loan guarantees induce a transfer from skilled to unskilled, and this transfer can be substantial, while the gains to the skilled from seeing loan pricing terms improve as a result of guarantees is relatively small. Second, we find that allocations are quite sensitive to the size of qualifying loans: Even modest limits on qualifying loan size invite very large borrowing - as perhaps intended by proponents - but also spur very large increases in default rates. As a result, loan guarantee programs transfer resources in significant amounts from all households to the lifetime poor. Under asymmetric information, the welfare gains are larger for all households, as the taxes required to finance the programs are smaller. Our work provides an answer for why, despite the potential welfare gains from expanding guarantees to consumer credit that thereby alleviate credit constraints for a marginalized population otherwise lacking collateral, public guarantees on unsecured consumer credit have not yet been implemented. The value of the program depends on how elastically credit demand and supply respond to default risk, which may be hard to estimate, and the programs are quite costly if too generous. ${ }^{27}$ As a practical matter, the forces at work in our model may well be part of explaining why student loan default rates hit 25 percent in the early 1990s, at which point the government increased monitoring and enforcement (recall also the similar findings of Lelarge, Sraer, and Thesmar [2010] in the French entrepreneurship context).

The preceding intuition will likely carry over to markets beyond the one for unsecured consumer credit, in particular for two areas that have seen some form of loan guarantee: federal student loans and home loans. It suggests that loans of the size guaranteed by a federal student loan program would have been likely to default at high rates, even under a relatively "partial" nature of the guarantee. Similarly, the FHA/VA and others have historically provided loan guarantees for mortgage loans. The calibrated costs of default measured in our model suggest strongly that larger loans, especially if covered more fully by a loan guarantee program, would lead to even greater debt and default than that predicted for the consumer credit market. Therefore, unless such loans are vetted carefully, one should expect a high take-up rate, a high subsequent failure rate, and nontrivial transfers from better-off households. Nonetheless, despite the risks involved, a main result of the article is that a limited program, specifically one where loan guarantees are made contingent on certain rare but disastrous events, can

\footnotetext{
27 An important caveat here is that in our model, the costs of default are assumed invariant to the level of default in the economy. Thus, a major loan guarantee program may meaningfully affect default costs. This is surely subject to at least some Lucas Critique-related problems. Nonetheless, endogenizing these costs is beyond the scope of the article.
} 
deliver net gains for all households. Such a policy seems worth exploring further. Of course, a caveat to the conclusion that targeting guarantees to those who have suffered a bad expense shock is that it may require additional resources to battle any moral hazard that might be present, especially when default is allowed upon getting any shock that is not a genuine catastrophe to households. Taken as a whole, our results suggest that loan guarantees can help, but care must be taken if policymakers intervene in credit markets through the use of loan guarantees.

Lastly, because the results reported in this article suggest that loan guarantees for household credit may be a powerful tool for altering steady-state consumption, our work should be of help for future examinations of the extent to which consumer lending and more importantly, consumer willingness to borrow, can be amplified to spur current consumption in business cycle contexts. The model of Gordon (2015) could possibly be adapted to this question.

\section{APPENDIX: QUANTITATIVE MODEL}

We now provide a detailed description of the quantitative model used here. As noted at the outset, it is essentially that of Athreya, Tam, and Young (2012b), modified to accommodate changes in loan pricing and taxes necessitated by loan guarantees.

\section{Preferences}

Households in the model economy live for a maximum of $J<\infty$ periods and face stochastic labor productivity and mortality risk. Households supply labor inelastically. ${ }^{28}$ Households differ along several dimensions over their life cycles according to an index of type, denoted $y$ and defined in what follows. Each household of age $j$ and type $y$ has a conditional probability $\psi_{j, y}$ of surviving to age $j+1$. Households retire exogenously at age $j^{*}<J$. Let $n_{j}$ denote the number of "effective" members in a household. Households value consumption per effective

\footnotetext{
${ }^{28}$ We abstract from elastic labor supply because it is known (e.g., Pijoan-Mas 2006) that under incomplete markets, households borrowing significant amounts tend to supply labor relatively inelastically, and for our study, this margin is unlikely to be crucial. It naturally implies that our welfare cost measurements may be biased, but it is unclear which direction that bias would go.
} 
household member $\frac{c_{j}}{n_{j}}$. They have identical additively separable isoelastic felicity functions with parameter $\sigma$, and possess a common discount factor $\beta$. To smooth consumption, all households have access to riskfree savings, and also debt that they may fully default on, subject to some costs. These costs reflect the variety of consequences that bankruptcy imposes on households, and need not be interpreted solely as "stigma," but include any such costs. A portion of these costs are represented by a nonpecuniary cost of filing for bankruptcy, denoted by $\lambda_{j, y}$, which we also permit to depend on household type $y$. Household preferences are therefore given by

$U\left(\left\{\frac{c_{j}}{n_{j}}\right\}_{j=1}^{J}\right)=\frac{1}{1-\sigma} E\left[\sum_{j=1}^{J} \beta^{j-1} \psi_{j, y}\left(\left(\left[\lambda_{j, y} d_{j}+\left(1-d_{j}\right)\right] \frac{c_{j}}{n_{j}}\right)^{1-\sigma}\right)\right]$,

where $d_{j}$ is the indicator function that equals unity when the household chooses to default in the current period (in which case $d_{j}=1$ ).

The existence of nonpecuniary costs of bankruptcy is strongly suggested by the calculations and evidence in Fay, Hurst, and White (1998) and Gross and Souleles (2002). The first article shows that a large measure of households would have "financially benefited" from filing for bankruptcy but did not, while both articles document significant unexplained variability in the probability of default across households after controlling for a large number of observables.

In this specification, a household with a relatively low value of $\lambda_{j, y}$ will obtain low value from any given expenditure on consumption $\left(c_{j}\right)$ in a period in which they file for bankruptcy. This is meant to reflect the increased transactions cost associated with obtaining utility via consumption expenditures in the period of a bankruptcy. Examples include increased "shopping time" arising from difficulty in obtaining short-term credit and payments services, locating rental housing and car services, as well as any stigma/psychological consequences. For convenience, we will sometimes refer to $\lambda_{j, y}$ as stigma in what follows; we intend it to be more encompassing. ${ }^{29}$ Because of the breadth of costs that $\lambda$ represents, we will allow it to vary stochastically over time and across individuals as a function of their type $y$, according to a transition function $p_{\lambda}$.

At the time of obtaining a loan, a household who expects to have a relatively low value of $\lambda$ next period will know that filing for

\footnotetext{
${ }^{29}$ Another possibility is that these households gain the benefits from bankruptcy without filing, as suggested by Dawsey and Ausubel (2004). Athreya et al. (2012) extends the benchmark model to include a delinquency state in which households do not formally file for bankruptcy but also do not service their debt.
} 
bankruptcy will result in a relatively high cost of obtaining any given level of marginal utility in the next period. Given the current marginal utility of consumption, consumption smoothing (i.e., keeping marginal utility in accordance with the standard Euler equation) under bankruptcy will therefore be costlier, all else equal, than for a household with a high value of $\lambda$. This is further amplified by the fact that households are not allowed to borrow in the same period as when they file for bankruptcy. For convenience, we will therefore refer to those whose value of $\lambda_{j, y}$ is relatively low as "low-risk" borrowers, and vice versa.

In addition to this nonpecuniary cost, there is an out-of-pocket pecuniary resource cost $\Lambda$ that represents all formal legal costs and other procedural costs of bankruptcy. Lastly, households are not allowed to borrow or save in the same period as a bankruptcy filing, to capture provisions guarding against fraud that are routinely applied in court. There are no other costs of bankruptcy in the model.

\section{Endowments}

Our focus on consumer credit makes it critical to allow for both uninsurable idiosyncratic risk. Consumer default, and hence the value of loan guarantees, is by all accounts strongly tied to individual-level uninsurable risk (see, e.g., Sullivan, Warren, and Westbrook [1999, 2000] and Chatterjee et al. [2007]). ${ }^{30}$ There are two sources of such risk in our model. First, households face shocks to their labor productivity, and because they are modeled as supplying labor inelastically, face shocks to their labor earnings. Second, households are susceptible to shocks to their net worth. The former represent shocks arising in the labor market more generally, and the latter represent sudden required expenditures arising from unplanned events such as sickness, divorce, and legal expenses.

In addition to the use of credit to deal with stochastic fluctuations in income and expenditures, consumer credit also likely serves, as noted earlier, as a tool for longer-term, more purely intertemporal smoothing in response to predictable, low-frequency changes in labor income, such as those coming with increased age and labor market experience. This leads us to specify, in addition to transitory and persistent shocks to income, a deterministic evolution in average labor productivity over the life cycle. This component of earnings will reflect most obviously

\footnotetext{
${ }^{30}$ In mortgage lending, loan guarantees protect lenders against house price fluctuations, which in turn are strongly tied to aggregate risk (or at least city-level risk). The full incorporation of the aggregate risk, private information, and limited commitment needed to analyze this specific class of guarantees remains an important topic for future work.
} 
one's final level of educational attainment, which is represented in the model as part of an agent's type, $y$.

Specifically, log labor income will be determined as the sum of four terms: the aggregate wage index $W$, a permanent shock $y$ realized prior to entry into the labor market, a deterministic age term $\omega_{j, y}$, and a persistent shock $e$ that evolves as an $\operatorname{AR}(1)$ process. The log of income at age- $j$ for type $-y$ is therefore given by

$$
\log W+\log \omega_{j, y}+\log y+\log e+\log \nu
$$

where

$$
\log \left(e^{\prime}\right)=\varsigma \log (e)+\epsilon^{\prime}
$$

and a purely transitory shock $\log (\nu)$. Both $\epsilon$ and $\log (\nu)$ are independent mean zero normal random variables with variances that are $y$-dependent and have distributions $p_{e}$ and $p_{v}$, respectively.

As for the risk of stochastic expenditures, we follow the literature (e.g., Chatterjee et al. 2007 and Livshits, MacGee, and Tertilt 2007), and specify a process $x_{j}$ to denote the expense shock to net worth that takes on three possible values $\left\{0, x_{1}, x_{2}\right\}$ from a probability distribution $p_{x}(\cdot)$ with i.i.d. probabilities $\left\{1-p_{x 1}-p_{x 2}, p_{x 1}, p_{x 2}\right\}$.

We will take agents' permanent type $y$ to reflect differences between households with permanent differences in human capital. Specifically, we will consider agents with three types of human capital: those who did not graduate high school, those who graduated high school, and those who graduated college. ${ }^{31}$ This partition of households follows Hubbard, Skinner, and Zeldes (1994). The central reason for allowing this heterogeneity is that the observed differences in mean life-cycle productivity for each of these types of agents gives them different incentives to borrow over the life cycle. In particular, college workers will have higher survival rates and a steeper hump in earnings; the second is critically important as it generates a strong desire to borrow early in the life cycle. They also face smaller shocks than the other two education groups. The life-cycle aspect of our model is key; in the data, while bankruptcies occur late into the life cycle for some (see, e.g., Livshits, MacGee, and Tertilt 2007), defaults are still skewed toward young households. ${ }^{32}$

\footnotetext{
${ }^{31}$ Mortality rates also differ by education, although this heterogeneity is of no consequence for our questions.

${ }^{32}$ See Sullivan, Warren, and Westbrook (2000).
} 


\section{Market Arrangement}

As stated earlier, to smooth consumption and save for retirement, households have access to both risk-free savings as well as one-period defaultable debt. The issuance and pricing of debt is modeled as a two-stage game in which households at any age $j$ first announce their desired asset position $b_{j}$, after which a continuum of lenders simultaneously announces a loan price $q$. As a result, a household issuing $b_{j}$ units of face value receives $q b_{j}$ units of the consumption good today. A household who issues debt with face value $b_{j}$ at age- $j$ is agreeing to pay $b_{j}$ in the event that they fully repay the loan, and pay zero otherwise (i.e., when they file for bankruptcy). The fact that nonrepayment can occur with positive probability in equilibrium means that lenders will not be willing to pay the full face value, even after adjusting for one-period discounting. Therefore, given any gross cost of funds $\widehat{R}$, we must have $q \leq 1 / \widehat{R}$.

As we will allow for both symmetric and asymmetric information, we introduce the following notation. Let $I$ denote the information set for a lender and $\widehat{\pi}: b \times I \rightarrow[0,1]$ denote the function that assigns a probability of default to a loan of size $b_{j}$ given information $I$. Clearly, since default risk assessed by lenders will depend in general on both their information and the size of the loan taken by a household, so will loan prices. Therefore, let loan pricing be given by the function $q\left(b_{j}, I\right)$. Under asymmetric information, we allow lenders to use the information revealed by the size of the loan request and lenders' knowledge of the distribution of household net worth in the economy to update their assessment of all current unobservables. Thus, lenders use their knowledge of both (i) optimal household decision making (i.e., their decision rules as a function of their state), and (ii) the endogenous distribution of households over the state vector. We will describe the determination of this function in detail below.

The household budget constraint during working life, as viewed immediately after the decision to repay or default on debt has been made, is given by

$$
c_{j}+q\left(b_{j}, I\right) b_{j}+\Lambda d_{j} \leq a_{j}+\left(1-\tau_{1}-\tau_{2}\right) W \omega_{j, y} y e \nu .
$$

$a_{j}$ is net worth after the current-period default decision $d_{j}$. Therefore, $a_{j}=b_{j-1}-x_{j}$ if $d_{j}=0$ and 0 if $d_{j}=1$. Households' default decisions also determine their available resources beyond removing debt, because default consumes real resources $\Lambda$, arising from court costs and legal fees. The last term, $\left(1-\tau_{1}-\tau_{2}\right) W \omega_{j, y} y e \nu$, is the after-tax level of current labor income, where $\tau_{1}$ is the flat-tax rate used to fund pensions and $\tau_{2}$ is the rate used to finance the loan guarantee program. Keep in mind also that implicit in the specification of the loan pricing function 
$q(\cdot)$ is the fact that if the household borrows an amount in excess of the guarantee limit, the price is that of an entirely nonguaranteed loan.

The budget constraint during retirement is

$$
c_{j}+q\left(b_{j}, I\right) b_{j}+\Lambda d_{j} \leq a_{j}+v W \omega_{j^{*}-1, y} y e_{j^{*}-1} \nu_{j^{*}-1}+\Upsilon W,
$$

where for simplicity we assume that pension benefits are composed of a fraction $v \in(0,1)$ of income in the last period of working life plus a fraction $\Upsilon \in(0,1)$ of average income $W$ (we normalize average individual labor earnings to 1$)$.

\section{Consumer's Problem}

The timing is as follows. In each period, all uncertainty is first realized. Thus, income shocks $e$ and $v$, the default $\operatorname{cost} \lambda$, and the current expense shock $x$ are all known before any decisions within the period are made. Following this, households must decide, if they have debt that is due in the current period, to repay or default. This decision, along with the realized shocks, then determines the resources the household has available in the current period. Given this, the household chooses current consumption and debt or asset holding with which to enter the next period, and the period ends.

Prior to making the current-period bankruptcy decision, a household can be fully described by $b_{j-1}$, the debt, if any, that is due in the current period, their type $y$, the pair of currently realized income shocks $e$ and $v$, their cost of default $\lambda$, the current realization of the shock to expenses, $x_{j}$, and their age $j .^{33}$

Letting $V(\cdot)$ denote the household's value function prior to the decision to default or repay, with primed variables denoting objects one period ahead, we have the following recursive description. If the household chooses to repay its debt $b_{j-1}$, and therefore sets $d_{j}=0$, then the value they derive from state $\left(b_{j-1}, y, e, \nu, \lambda, x, j\right)$ is

$\max _{c, b_{j}}\left\{\begin{array}{c}v^{d=0}\left(b_{j-1}, y, e, \nu, \lambda, x, j\right)= \\ \left(\frac{c_{j}}{n_{j}}\right)^{1-\sigma}+ \\ \beta \psi_{j, y}\left(\sum_{e^{\prime}, \nu^{\prime}, \lambda^{\prime}, x^{\prime}} p_{x}\left(x^{\prime}\right) p_{e}\left(e^{\prime} \mid e\right) p_{\nu}\left(\nu^{\prime}\right) p_{\lambda}\left(\lambda^{\prime} \mid \lambda\right) V\left(b, y, e^{\prime}, \nu^{\prime}, \lambda^{\prime}, x^{\prime}, j+1\right)\right)\end{array}\right\}$

subject to the budget constraint

\footnotetext{
${ }^{33}$ To avoid repetition, we display only the value functions during working life; retirement is entirely analogous.
} 


$$
c_{j}+q\left(b_{j}, I\right) b_{j}+x_{j} \leq b_{j-1}+\left(1-\tau_{1}-\tau_{2}\right) W \omega_{j, y} y e \nu .
$$

If the household has chosen bankruptcy for the current period $\left(d_{j}=\right.$ 1 ), since we disallow credit market activity in the period of bankruptcy, which implies $b_{j}=0$, we obtain

$$
\left.\begin{array}{c}
v^{d=1}\left(b_{j-1}, y, e, \nu, \lambda, x, j\right)= \\
\left(\lambda_{j, y} \frac{c_{j}}{n_{j}}\right)^{1-\sigma}+ \\
\beta \psi_{j, y}\left(\sum_{e^{\prime}, \nu^{\prime}, \lambda^{\prime}, x^{\prime}} p_{x}\left(x^{\prime}\right) p_{e}\left(e^{\prime} \mid e\right) p_{\nu}\left(\nu^{\prime}\right) p_{\lambda}\left(\lambda^{\prime} \mid \lambda\right) V\left(0, y, e^{\prime}, \nu^{\prime}, \lambda^{\prime}, x^{\prime}, j+1\right)\right)
\end{array}\right\},
$$

subject to the budget constraint:

$$
c_{j}+\Lambda \leq\left(1-\tau_{1}-\tau_{2}\right) W \omega_{j, y} y e \nu .
$$

Notice that both debt due in the current period, $b_{j-1}$, and the current expenditure shock realization, $x_{j}$, get removed by bankruptcy, and hence disappear, when comparing the budget constraint under bankruptcy to one under nonbankruptcy. By contrast, the resource- and nonpecuniary costs, $\Lambda$, and $\lambda_{j, y}$, respectively, both appear.

Given this, prior to the bankruptcy decision, the current-period value function is

$$
\begin{gathered}
V\left(b_{j-1}, y, e, \nu, \lambda, x, j\right)= \\
\max \left\{v^{d=1}\left(b_{j-1}, y, e, \nu, \lambda, x, j\right), v^{d=0}\left(b_{j-1}, y, e, \nu, \lambda, x, j\right)\right\} .
\end{gathered}
$$

For the full information setting we assume $I$ contains the entire state vector for the household; let $I=(y, e, \nu, x, \lambda, j)$. Abusing notation slightly, let $d(\cdot)$ now denote the decision rule governing default. As described earlier, this function drives the decision to repay a given debt or not, and hence depends on the full household state vector. Letting non-primed objects represent current period decisions, and using primed variables for objects dated one period ahead, we have the following zero profit condition for the intermediary. Simply put, it requires that the probability of default used to price debt must be consistent with that observed in the stationary equilibrium, implying that

$$
\begin{gathered}
\widehat{\pi}^{f i}(b, y, e, \lambda, j)= \\
\sum_{e^{\prime}, \nu^{\prime}, \lambda^{\prime}, x^{\prime}} d\left(b, e^{\prime}, \nu^{\prime}, x^{\prime}, \lambda^{\prime}, j+1\right) p_{e}\left(e^{\prime} \mid e\right) p_{\nu}\left(\nu^{\prime}\right) p_{\lambda}\left(\lambda^{\prime} \mid \lambda\right) \pi_{x}\left(x^{\prime}\right) .
\end{gathered}
$$

Since $d\left(b, e^{\prime}, \nu^{\prime}, x^{\prime}, \lambda^{\prime}, j+1\right)$ specifies whether or not the agent will default in state $\left(e^{\prime}, \nu^{\prime}, x^{\prime}, \lambda^{\prime}\right)$ tomorrow at debt level $b$, integrating over all 
such events one period hence produces the relevant estimated default risk $\widehat{\pi}^{f i}$. This expression also makes clear that knowledge of the persistent components $(e, \lambda)$ is relevant for predicting default probabilities, and the more persistent these characteristics are, the more useful they become in assessing default risk.

\section{Asymmetric Information}

As we noted at the outset, earlier work, starting with Narajabad (2012), and including the work of Sánchez (2009) and Athreya, Tam, and Young (2012a), found that in past decades, unsecured credit market outcomes may well have been affected by informational frictions. In the latter article, asymmetric information governing individual-level costs of bankruptcy were shown to be consistent with a variety of features of the data from the 1980s and earlier. Thus, to evaluate the implications of loan guarantees under asymmetric information, we assume that nonpecuniary default costs, $\lambda_{j, y}$, is unobservable. With the exception of current household net worth following the bankruptcy decision in a period (which we denoted by $a$ ) all other household attributes, including educational attainment, age, and the current realization of the persistent component of income are assumed observable. To be clear, using household decisions rules and the distribution of households over the state space to infer a borrower's current net worth, $a$, is not useful because the net worth $a$ is relevant to forecasting income, default risk, or anything else; it is not. Rather, it is because lenders want to draw a more precise inference on the current values of the persistent aspects of a household's state. In this case the inference is about the current realization of a household's $\lambda$, something that is clearly relevant to assessing default risk.

Let $p^{*}(\lambda \mid b, y, e, \nu, x, j)$ denote the equilibrium conditional probability of a household having a realized value of $\lambda$, given that they have observable characteristics $y, e, \nu, x, j$, and that they have issued bonds of $b$ units of face value. To construct the equilibrium assessment of default risk, $\pi^{*}(\cdot)$, lenders use their knowledge of household decision making and the joint (conditional) distribution of households over the state space to arrive at a probability distribution for the current value of a household's nonpecuniary default cost. ${ }^{34}$ The best estimate of default risk is then given by

$$
\widehat{\pi}^{p i}(b, y, e, \nu, x, j)=\sum_{\lambda} p^{*}(\lambda \mid b, y, e, \nu, x, j) \widehat{\pi}^{f i}(b, y, e, \nu, x, \lambda, j) .
$$

\footnotetext{
${ }^{34}$ See Athreya, Tam, and Young (2012b) for details.
} 


\section{Equilibrium in the Credit Market}

Here, we follow Athreya, Tam, and Young (2012b), and employ the Perfect Bayesian Equilibrium (PBE) concept to define equilibrium in the game between borrowers and lenders. Denote the state space for households by $\Omega=\mathcal{B} \times \mathcal{Y} \times \mathcal{E} \times \mathcal{V} \times \mathcal{L} \times \mathcal{J} \times\{0,1\} \subset \mathcal{R}^{6} \times \mathcal{Z}_{++} \times\{0,1\}$ and space of information as $\mathcal{I} \subset \mathcal{Y} \times \mathcal{E} \times \mathcal{V} \times \mathcal{L} \times \mathcal{J} \times\{0,1\}$. Let the stationary joint distribution of households over the state be given by $\Gamma(\Omega)$. Let the stationary equilibrium joint distribution of households over the state space $\Omega$ and loan requests $b^{\prime}$ be derived from the decision rules $\left\{b^{\prime *}(\cdot)\right.$, $\left.d^{*}(\cdot)\right\}$ and $\Gamma(\Omega)$, and be denoted by $\Psi^{*}\left(\Omega, b^{\prime}\right)$. Given $\Psi^{*}\left(\Omega, b^{\prime}\right)$, let $\mu^{*}\left(b^{\prime}\right)$ be the fraction of households (i.e., the marginal distribution of $\left.b^{\prime}\right)$ requesting a loan of size $b^{\prime}$. Lastly, let the common beliefs of lenders on the household's state, $\Omega$, given $b^{\prime}$, be denoted by $\Upsilon^{*}\left(\Omega \mid b^{\prime}\right) .{ }^{35}$

Definition 1 A PBE for the credit market game of incomplete information consists of (i) household strategies for borrowing $b^{\prime *}: \Omega \rightarrow \mathcal{R}$ and default $d^{*}: \Omega \times \lambda \times \mathcal{E} \times \mathcal{V} \rightarrow\{0,1\}$, (ii) lenders' strategies for loan pricing $q^{*}: \mathcal{R} \times \mathcal{I} \rightarrow\left[0, \frac{1}{1+r}\right]$ such that $q^{*}$ is weakly decreasing in $b^{\prime}$, and (iii) lenders' common beliefs about the borrower's state $\Omega$ given a loan request of size $b^{\prime}, \Upsilon^{*}\left(\Omega \mid b^{\prime}\right)$, that satisfy the following:

1. Households optimize: Given lenders' strategies, as summarized in the locus of prices $q^{*}\left(b^{\prime}, I\right)$, decision rules $\left\{b^{\prime *}(\cdot), d^{*}(\cdot)\right\}$ solve the household problem.

2. Lenders optimize given their beliefs: Given common beliefs $\Upsilon^{*}\left(\Omega \mid b^{\prime}\right), q^{\prime *}$ is the pure-strategy Nash equilibrium under oneshot simultaneous-offer loan-price competition.

3. Beliefs are consistent with Bayes' rule wherever possible: $\Upsilon^{*}\left(\Omega \mid b^{\prime}\right)$ is derived from $\Psi^{*}\left(\Omega, b^{\prime}\right)$ and household decision rules using Bayes rule whenever $b$ is such that $\mu^{*}\left(b^{\prime}\right)>0$.

Equilibria are located through an iterative procedure. The interested reader is directed to the online appendix in Athreya, Tam, and Young (2012b), where we discuss the computational procedure used to solve for equilibria. As a quick summary, we define an iterative procedure that maps a set of pricing functions back into themselves, whose fixed points are PBE of the game between lenders and borrowers. This

${ }^{35}$ Recall that the stationary distribution of households over the state space alone is given by $\Gamma(\cdot)$. 
procedure is monotonic, so starting from the upper limit yields convergence to the largest fixed point. ${ }^{36}$

\section{Government}

The government's budget constraint is motivated by two expenditures it must finance. Most importantly, it must finance payments to a lender to honor the loan guarantee program. Letting $\Gamma(a, y, e, \nu, x, \lambda, j)$ denote the invariant cumulative distribution function of households over the states, this is given by $\operatorname{tax} \tau_{2}$, which must satisfy

$$
\begin{aligned}
& \tau_{2} W \int y \omega_{j, y} e \nu d \Gamma\left(a, y, e, \nu, x, \lambda, j<j^{*}\right)= \\
& \int \psi_{j+1 \mid j} \frac{\widehat{\pi}(b(a, y, e, \nu, x, \lambda, j), I)}{1+r+\phi} \max (0, b(a, y, e, \nu, x, \lambda, j)+\vartheta) \times \\
& \frac{\theta b(a, y, e, \nu, x, \lambda, j)}{b(a, y, e, \nu, x, \lambda, j)+\vartheta} d \Gamma(a, y, e, \nu, x, \lambda, j) .
\end{aligned}
$$

In addition to financing loan guarantees, the government funds pension payments to retirees and to finance the loan guarantee system. The government budget constraint for pensions is

$$
\begin{gathered}
\tau_{1} W \int\left(y \omega_{j, y} e \nu\right) d \Gamma\left(a, y, e, \nu, x, \lambda, j<j^{*}\right)= \\
W \int\left(v \omega_{j^{*}-1, y} y e_{j^{*}-1} \nu_{j^{*}-1}+\Upsilon\right) d \Gamma\left(a, y, e, \nu, x, \lambda, j \geq j^{*}\right) .
\end{gathered}
$$

\section{Wage Determination}

For both simplicity and substantive reasons, we assume constant and exogenous factor prices in our welfare calculations. In particular, we assume that the risk-free rate $r$ is exogenous and determined by the world market for credit. Our approach follows several articles in the literature in abstracting from feedback effects onto risk-free rates of saving coming from changes in borrowing in the unsecured credit market, including Livshits, MacGee, and Tertilt (2007). This is a convenient abstraction and will be reasonable as long as guarantee programs are not inordinately generous.

\footnotetext{
${ }^{36}$ Uniqueness cannot be ensured, since $q=0$ is a fixed point of our mapping. However, simple sufficient conditions exist to rule out $q=0$ as the maximal fixed point; $\Lambda>0$ is enough to guarantee the existence of an interval $[-\Lambda, 0]$ of risk-free debt. Sufficient conditions that ensure the existence of nontrivial default risk in equilibrium are not known.
} 
Specifically, given $r$, profit maximization by domestic production firms implies that

$$
W=(1-\alpha)\left(\frac{r}{\alpha}\right)^{\frac{\alpha}{\alpha-1}}
$$

where $\alpha$ is capital's share of income in a Cobb-Douglas aggregate production technology.

\section{Stationary Equilibrium}

We have already given the definition of equilibrium for the game between borrowers and lenders. The outcomes of that interaction were, of course, part of a larger fixed-point problem that included, among other things, the joint distribution of households over the state space, $\Gamma(\cdot)$, and the tax rates $\tau_{1}$ and $\tau_{2}$ needed to fund transfers and loan guarantees, respectively. But this joint distribution depended on household borrowing behavior, which in turn influenced the construction of $\Gamma(\cdot)$. Given this feedback, we will focus throughout on stationary equilibria in which all aggregate objects including, critically, the joint distribution $\Gamma(\cdot)$, remain constant over time under the decision rules that arise from household and creditor optimization.

Computing stationary equilibria requires two layers of iteration. We first specify the wage rate, interest rate, tax rates, and public sector transfer and loan guarantee policies. This allows us to solve the household's decision problem and locate the associated stationary distribution of households over the state space - all for a given guess of the equilibrium loan-pricing locus $q(\cdot)$. Our use of a risk-free rate-taking open economy allows us to iterate on the function $q(\cdot)$ without having to deal with any additional feedback from loan pricing to risk-free interest rates and wages. Once we have located a price function that is a fixed point under the stationary distribution induced by optimal household decision making (which we can denote by $q^{*}(\cdot)$ ), we need to check if the government budget constraint holds. Here, we must iterate again, this time on transfers and taxes. We use Brent's method to solve for the tax rate that satisfies the government budget constraint (re-solving for the fixed-point loan pricing function $q^{*}(\cdot)$ each time); whenever Laffer curve considerations arise, we choose the lower tax rate.

\section{Parametrization}

To assign values to model parameters, we proceed first by imposing standard values from the literature for measures of income risk, out-ofpocket expenses, risk aversion, and demographics. We then calibrate 
the remaining model parameters, which are those governing bankruptcy costs and the discount factor. The goal is to match, as well as possible, key facts about bankruptcy and unsecured credit markets in the United States, given income risk, risk aversion, and demographics. As discussed earlier, we follow the literature by calibrating to recent data and assuming symmetric information between borrowers and lenders.

The parametrization is relatively parsimonious and largely standard. First, as mentioned above, we directly assign values to household level income risk and risk aversion at values standard in the literature. The model period is taken to be one year. The income process is taken from Hubbard, Skinner, and Zeldes (1994), who estimate separate processes for non-high school (NHS), high school (HS), and collegeeducated (Coll) workers for the period 1982-1986. ${ }^{37}$ Figure 3 displays the path $\omega_{j, y}$ for each type; the large hump present in the profile for college-educated workers implies that they will want to borrow early in life to a greater degree than the other types (despite their effective discount factor being somewhat higher because of higher survival probabilities). The process is discretized with 15 points for $e$ and 3 points for $\nu$. The resulting processes are

$$
\begin{aligned}
\log \left(e^{\prime}\right) & =0.95 \log (e)+\epsilon^{\prime} \\
\epsilon & \sim N(0,0.033) \\
\log (\nu) & \sim N(0,0.04)
\end{aligned}
$$

for non-high school agents,

$$
\begin{aligned}
\log \left(e^{\prime}\right) & =0.95 \log (e)+\epsilon^{\prime} \\
\epsilon & \sim N(0,0.025) \\
\log (\nu) & \sim N(0,0.021)
\end{aligned}
$$

for high school agents, and

$$
\begin{aligned}
\log \left(e^{\prime}\right) & =0.95 \log (e)+\epsilon^{\prime} \\
\epsilon & \sim N(0,0.016) \\
\log (\nu) & \sim N(0,0.014)
\end{aligned}
$$

for college agents. We normalize average income to 1 in model units, and in the data one unit roughly corresponds to $\$ 40,000$ in income. When we construct the invariant distribution of the model, we assume

\footnotetext{
${ }^{37}$ In Athreya, Tam, and Young (2009) we study the effect of the rise in the volatility of labor income in the United States and find the effect on the unsecured credit market to be quantitatively small; the key parameter for default is the persistence of the shocks. We would find similar numbers if we adjusted the variance of the shocks upward to conform to more recent data.
} 
households are born with zero assets and draw their first shocks from the stationary distributions.

To assign values for the idiosyncratic risk of out-of-pocket expenses, we choose the parameters for the expenditure shock $x_{j}$ to be the annualized equivalent of those used in Livshits, MacGee, and Tertilt (2007). For pensions, we set $v=0.35$ and $\Upsilon=0.2$, yielding an average replacement rate of 55 percent, and assume an exogenous retirement age of $j^{*}=45$. Relative risk aversion is set to $\sigma=2$, as is standard, and a value that also avoids overstating the insurance problem faced by households. Lastly, with respect to demographics, we set the measures of the college (Coll), high school (HS), and non-high school (NHS) agents to 20,58 , and 22 percent, respectively, and the maximum lifespan to $J=65$, corresponding to a calendar age of 85 years.

Table 1 in the main text displays the targeted moments and the implied ones from the model. ${ }^{38}$ Table 2 in the main text displays the parameters associated with this calibration, along with the other parameters of the model (such as the cost of default $\Lambda$, which is set to match the observed $\$ 1,200$ filing cost). First, the default rates, measured as filings for Chapter 7 bankruptcy, are very close to the data. Second, the model does fairly well at matching the debt/income ratios in the data, measured as credit card debt divided by income (from the Survey of Consumer Finances 2004), although it reverses the order by understating debt for college types and overstating it for non-high school types. Lastly, the model generates a somewhat higher proportion of the observed fraction of borrowers while yielding smaller value of discharged debt to income ratio than currently measured. ${ }^{39}$

To parameterize the nonpecuniary costs of bankruptcy while limiting free parameters, we represent $\lambda$ by a two-state Markov chain with realizations $\left\{\lambda_{L, y}, \lambda_{H, y}\right\}$ that are independent across households, but serially dependent with a symmetric transition matrix $P_{\lambda}$ :

$$
P_{\lambda}=\left[\begin{array}{cc}
p_{\lambda} & 1-p_{\lambda} \\
1-p_{\lambda} & p_{\lambda}
\end{array}\right]
$$

The calibrated process suggests that nonpecuniary costs of bankruptcy are largely in the nature of a "type" for any given household. This interpretation arises because the benchmark calibration reveals $\lambda$ to be very persistent, and therefore very unlikely to change during the part

\footnotetext{
${ }^{38}$ The calibrated parameters are obtained by minimizing the (equally weighted) sum of squared deviations between the data and moments from the invariant distribution of the model. Since the model is not linear, we cannot guarantee that there exists a set of parameters that makes this criterion zero; indeed, we find that such a vector does not seem to exist.

${ }^{39}$ If we had data on discharge by education type, we could permit the persistence of $\lambda$ to vary by type and possibly match the aggregates more closely.
} 
of life where unsecured credit is useful. This persistence is also what makes the model consistent with the observed ability of households to borrow substantial amounts but still default at a nontrivial rate. Despite this "implicit collateral," debts discharged in bankruptcy are still higher in the data; however, the discharge ratio from the data (obtained as the median debts discharged in bankruptcy divided by the median income of filers taken from the survey data of Sullivan, Warren, and Westbrook [2000]) is likely an overestimate, as it includes small business defaults that are generally large and not present in the model. The size of the values for $\lambda$ are relatively large, implying that even the low cost types view default as equivalent to a loss of nearly 10 percent of consumption; thus, the primary source of implicit collateral in this model is stigma rather than pecuniary costs.

Table 3 in the main text presents a decomposition of defaults according to the various combinations of expense shock and stigma. The median shock for $x$ and the high value of $\lambda$ constitute only 3.55 percent of the population but are responsible for 58.11 percent of the defaults under symmetric information, while the high shock for $x$ and high value for $\lambda$ are 0.23 percent of the population and 6.66 percent of the defaults. Thus, defaults are clearly skewed toward households that experience an expenditure shock, consistent with the model of Livshits, MacGee, and Tertilt (2007).

Lastly, while omitted from the tables for brevity, the other relevant probability is that of the likelihood of default given the receipt of an expenditure shock. This distribution yields two pieces of information about the model. First, getting an expenditure shock, particularly the largest one, greatly increases the likelihood of default, all else equal. Second, the vast majority of households who receive such a shock still do not default. The reason for this is that the power of such shocks to drive default, while nontrivial, is still naturally limited by the wealth positions households take on as they move through the life cycle. Default is most likely to happen when one has substantial debts at the same time that one receives such a shock. This rules out relatively older households from being very susceptible; as seen in Figure 6, they have, in the main, already begun saving for retirement. ${ }^{40}$

\footnotetext{
${ }^{40}$ For agents with the relatively high value for $\lambda$ in the model: High expense shock: $26 \%$

Median expense shock: $15 \%$

Low expense shock (a value of zero) $=1 \%$

For agents with the relatively low value for $\lambda$ in the model:

High expense shock: $17 \%$

Median expense shock: $2 \%$

Low expense shock (a value of zero) $=0 \%$

The numbers are very similar under asymmetric information.
} 


\section{REFERENCES}

Aiyagari, S. Rao. 1994. "Uninsured Idiosyncratic Risk and Aggregate Saving." Quarterly Journal of Economics 109 (August): 659-84.

Andolfatto, David. 2002. "A Theory of Inalienable Property Rights." Journal of Political Economy 110 (April): 382-93.

Athreya, Kartik B. 2008. "Default, Insurance, and Debt over the Life-Cycle." Journal of Monetary Economics 55 (May): 752-74.

Athreya, Kartik B., Juan M. Sánchez, Xuan S. Tam, and Eric R. Young. 2012. "Bankruptcy and Delinquency in a Model of Unsecured Credit." Federal Reserve Bank of St. Louis Working Paper 2012-042A.

Athreya, Kartik B., Xuan S. Tam, and Eric R. Young. 2009. "Unsecured Credit Markets Are Not Insurance Markets." Journal of Monetary Economics 55 (January): 83-103.

Athreya, Kartik B., Xuan S. Tam, and Eric R. Young. 2012a. "Debt Default and the Insurance of Labor Income Risk." Federal Reserve Bank of Richmond Economic Quarterly 98 (Fourth Quarter): 255-307.

Athreya, Kartik B., Xuan S. Tam, and Eric R. Young. 2012b. "A Quantitative Theory of Information and Unsecured Credit." American Economic Journal: Macroeconomics 4 (July): 153-83.

Becker, Gary S. 1967. Human Capital and the Personal Distribution of Income: An Analytical Approach (Woytinsky lecture). Ann Arbor, Mich.: Institute of Public Administration.

Calem, Paul S., Michael B. Gordy, and Loretta J. Mester. 2006. "Switching Costs and Adverse Selection in the Market for Credit Cards: New Evidence." Journal of Banking and Finance 30 (June): 1,653-85.

Castaneda, Ana, Javier Díaz-Giménez, and José-Víctor Ríos-Rull. 2003. "Accounting for Earnings and Wealth Inequality." Journal of Political Economy 111 (August): 818-57.

Chaney, Paul, and Anjan Thakor. 1985. "Incentive Effects of Benevolent Intervention: The Case of Government Loan Guarantees." Journal of Public Economics 26 (March): 169-89. 
Chatterjee, Satyajit, P. Dean Corbae, Makoto Nakajima, and José-Víctor Ríos-Rull. 2007. "A Quantitative Theory of Unsecured Consumer Credit with Risk of Default." Econometrica 75 (November): 1,525-90.

Dávila, Julio, Jay H. Hong, Per Krusell, and José-Víctor Ríos-Rull. 2012. "Constrained Efficiency in the Neoclassical Growth Model with Uninsurable Idiosyncratic Shocks." Econometrica 80 (November): 2,431-67.

Dawsey, Amanda E., and Lawrence M. Ausubel. 2004. "Informal Bankruptcy." Working Paper (April).

Dubey, Pradeep, John Geanakoplos, and Martin Shubik. 2005. "Default and Punishment in General Equilibrium." Econometrica 73 (January): 1-37.

Fay, Scott A., Erik Hurst, and Michelle J. White. 1998. "The Bankruptcy Decision: Does Stigma Matter?" University of Michigan Working Paper 98-01 (January).

Gale, William G. 1990. "Federal Lending and the Market for Credit." Journal of Public Economics 42 (July): 177-93.

Gale, William G. 1991. "Economic Effects of Federal Credit Programs." American Economic Review 81 (March): 133-52.

Ghent, Andra C., and Marianna Kudlyak. 2011. "Recourse and Residential Mortgage Default: Evidence from U.S. States." Review of Financial Studies 24 (June): 3,139-86.

Gordon, Grey. 2015. "Evaluating Default Policy: The Business Cycle Matters." Quantitative Economics. Available at: www.qeconomics.org/ojs/forth/372/372-2.pdf.

Gross, David B., and Nicholas S. Souleles. 2002. "An Empirical Analysis of Personal Bankruptcy and Delinquency." Review of Financial Studies 15 (March): 319-47.

Hubbard, R. Glenn, Jonathan Skinner, and Stephen P. Zeldes. 1994. "The Importance of Precautionary Motives for Explaining Individual and Aggregate Saving." Carnegie-Rochester Conference Series on Public Policy 40 (June): 59-125.

Innes, Robert. 1990. "Investment and Government Intervention in Credit Markets when there is Asymmetric Information." Journal of Public Economics 46 (December): 347-81.

Jappelli, Tullio. 1990. "Who is Credit Constrained in the U.S. Economy?" Quarterly Journal of Economics 105 (February): 219-34. 
Jeske, Karsten, Dirk Krueger, and Kurt Mitman. 2010. "Housing and the Macroeconomy: The Role of Implicit Guarantees for Government Sponsored Enterprises." Working Paper.

Jia, Ye. 2013. "Small Business Loan Guarantees as Insurance Against Aggregate Risks." The B.E. Journal of Macroeconomics 13 (January): 455-79.

Lacker, Jeffrey M. 1994. "Does Adverse Selection Justify Government Intervention in Loan Markets?" Federal Reserve Bank of Richmond Economic Quarterly 80 (Winter): 61-95.

Lelarge, Claire, David Sraer, and David Thesmar. 2010. "Entrepreneurship and Credit Constraints: Evidence from a French Loan Guarantee Program." In International Differences in Entrepreneurship, edited by Josh Lerner and Antoinette Schoar. Chicago: University of Chicago Press, 243-73.

Li, Wenli. 1998. "Government Loan Guarantee and Grant Programs: An Evaluation." Federal Reserve Bank of Richmond Economic Quarterly 84 (Fall): 25-51.

Li, Wenli. 2002. "Entrepreneurship and Government Subsidies: A General Equilibrium Analysis." Journal of Economic Dynamics and Control 26 (September): 1,815-44.

Livshits, Igor, James MacGee, and Michèle Tertilt. 2007. "Consumer Bankruptcy: A Fresh Start." American Economic Review 97 (March): 402-18.

Malysheva, Nadezhda, and John R. Walter. 2013. "How Large Has the Federal Financial Safety Net Become?" Federal Reserve Bank of Richmond Working Paper 10-03R (March).

Narajabad, Borghan N. 2012. "Information Technology and the Rise of Household Bankruptcy." Review of Economic Dynamics 15 (October): 526-50.

Pijoan-Mas, Josep. 2006. "Precautionary Savings or Working Longer Hours?" Review of Economic Dynamics 9 (April): 326-52.

Sánchez, Juan. 2009. "The Role of Information in the Rise of Consumer Bankruptcy." Federal Reserve Bank of Richmond Working Paper 2009-4 (April).

Smith, Bruce D., and Michael J. Stutzer. 1989. "Credit Rationing and Government Loan Programs: A Welfare Analysis." Real Estate Economics 17 (2): 177-93. 
Sullivan, Teresa A., Elizabeth Warren, and Jay Lawrence Westbrook. 1999. As We Forgive Our Debtors: Bankruptcy and Consumer Credit in America. New York: Oxford University Press.

Sullivan, Teresa A., Elizabeth Warren, and Jay Lawrence Westbrook. 2000. The Fragile Middle Class: Americans in Debt. New Haven, Conn.:Yale University Press.

Tam, Xuan S. 2009. "Long Term Contracts in Unsecured Credit Markets." Manuscript.

Telyukova, Irina A. 2013. "Household Need for Liquidity and the Credit Card Debt Puzzle." Review of Economic Studies 80 (January): 1,148-77.

Walter, John R., and John A. Weinberg. 2002. "How Large is the Federal Financial Safety Net?" CATO Journal 21 (Winter): 369-94.

Williamson, Stephen. 1994. "Do Informational Frictions Justify Federal Credit Market Programs?" Journal of Money, Credit and Banking 26 (August): 523-44.

Zame, William R. 1993. "Efficiency and the Role of Default when Security Markets are Incomplete." American Economic Review 83 (December): 1,142-64.

Zeldes, Stephen P. 1989. "Consumption and Liquidity Constraints: An Empirical Investigation." Journal of Political Economy 97 (April): 305-46. 